\title{
Análise de sistemas de medição de desempenho na indústria da construção
}

\author{
Analysis of performance measurement systems in the \\ construction industry
}

\begin{abstract}
Luís Felipe Cândido
Sérgio Henrique de Oliveira Lima José de Paula Barros Neto

Resumo

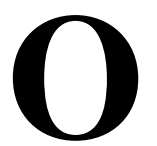

crescente debate sobre medição de desempenho entre profissionais e entre pesquisadores da área de gestão organizacional ainda não foi suficiente para consolidar as práticas de medição na indústria da construção. $\mathrm{O}$ presente trabalho tem por objetivo identificar as oportunidades para o aprimoramento dos sistemas de medição de desempenho na Construção. Para tanto, foram avaliados 22 modelos identificados na literatura nacional e internacional dos últimos 25 anos, aplicando protocolo de análise proposto neste estudo, e validado por especialistas. A partir do mapeamento das principais características, papéis e processos das práticas de medição no setor, da avaliação realizada concluiu-se que há necessidade de melhorias (i) no processamento dos dados, integrando-o à rotina organizacional, (ii) na gestão da informação, melhorando os mecanismos de geração de conhecimentos, (iii) na conexão da avaliação com um sistema de recompensas, e (iv) na revisão sistemática, quanto à sua utilidade, eficiência e consistência geral, não apenas de seus indicadores individuais. Propôs-se, ainda, um framework que apresenta uma visão holística do processo de medição, enfatizando a diferença entre sistema de indicadores e de medição de desempenho. Uma agenda de pesquisa foi sugerida, a partir das lacunas e oportunidades de melhoria encontrados.
\end{abstract}

Palavras-chave: Gestão da construção. Sistema de medição de desempenho. Gestão estratégica.

Luís Felipe Cândido Universidade Federal do Ceará Fortaleza - CE - Brasil

Sérgio Henrique de Oliveira

Lima

Universidade Federal do Ceará Fortaleza - CE - Brasil

José de Paula Barros Neto Universidade Federal do Ceará Fortaleza - CE - Brasil

Recebido em 16/03/15 Aceito em 09/12/15

\section{Abstract}

The debate about performance measurement is growing among professionals and researchers, but it is still insufficient to consolidate measurement practices in the construction industry. This study aims to identify opportunities for improvement in performance measurement systems in the construction industry, analysing 22 models found in the literature from the last 25 years. These models were evaluated by applying a protocol proposed in this study and a subsequent validation process by experts. Through the mapping of the key features, roles and processes of measurement practices, it was possible to conclude that the following improvements are necessary: (i) in data processing, integrating it into the company' routine, (ii) in information management, improving actions to generate knowledge, (iii) establishing a connection between assessment and a rewards system, and (iv) in a systematic review not only of individual indicators, but of the usability, efficiency and overall consistency of those indicators. Furthermore, we propose a framework that presents a holistic view of the measurement process, emphasizing the differences between indicator systems and performance measurement systems. We suggest a research agenda based on the gaps and opportunities for improvement detected.

Keywords: Construction management. Performance measurement systems. Strategic management. 


\section{Introdução}

Apesar de seu crescente desenvolvimento tecnológico, a indústria da construção ainda encontra barreiras e dificuldades de gerenciamento devido à natureza complexa dos empreendimentos de construção (HORSTMAN; WITTEVEEN, 2013). Essas barreiras e dificuldades impactam negativamente o desempenho dos projetos, sendo comum observar orçamentos excedidos, atrasos de cronograma, baixa qualidade e baixa produtividade no processo construtivo (GONZÁLEZ et al., 2014).

A falta de informações sobre o comportamento e o desempenho do projeto ao longo de sua execução é destacada como uma das causas desses problemas, uma vez que a medição de desempenho em empreendimentos de construção tem sido dominada por medidas convencionais de tempo, custo e qualidade (TOOR; OGUNLANA, 2010).

Esses aspectos já não suprem a necessidade das empresas de evoluir de maneira consistente, obtendo ganhos de aprendizagem, capitalizando recursos para novos empreendimentos, fomentando a inovação, a segurança, a qualidade de vida no trabalho, e, ainda assim, de atender às diferentes expectativas e interesses de todos os stakeholders (HORSTMAN; WITTEVEEN, 2013; KAGIOGLOU; COOPER; AQUAD, 2001; TOOR; OGUNLANA, 2010).

Nesse sentido diversos esforços foram empreendidos por acadêmicos e profissionais que analisaram como as empresas poderiam informar a seus stakeholders a riqueza gerada por seus empreendimentos, projetos específicos, ou ainda pela empresa como um todo. Entre 1994 e 1996, por exemplo, 3.615 artigos foram publicados sobre o tema "medição de desempenho" (NEELY, 1999).

Entretanto, essa relevante produção se deu no âmbito de disciplinas como Contabilidade, Estratégia, Recursos Humanos, Produção e Gestão de Operações, Marketing, Comportamento Organizacional e Gestão Estratégica, entre outras. Especificamente na indústria da construção, segundo argumentam Deng, Smyth e Anvuur (2012), a evolução dos sistemas ainda é lenta.

Apesar de os gestores da indústria da construção contarem com uma extensa lista de indicadores, autores apontam como principais dificuldades a falta de distinção entre o que são critérios de sucesso e fatores de sucesso (COOKE-DAVIES, 2002; TOOR; OGUNLANA, 2010) e a não distinção entre indicadores ligados aos processos (KPI), aos resultados do sistema de produção
(KPO) e às medidas de percepção (PEKURI; HAAPASALO; HERRALA, 2011).

Cooke-Davies (2002) e Toor e Ogunlana (2010) apontam essa compreensão difusa como deficiências que podem dificultar a correta implantação e utilização de sistemáticas de medição de desempenho.

Outro aspecto crítico é a definição de sucesso de um projeto. A construção é uma indústria baseada em projetos, e como tal é interessante que a medição de desempenho se concentre na performance destes (PEKURI; HAAPASALO; HERRALA, 2011). Assim, deve-se levar em consideração que cada empreendimento é um projeto único, que possui desafios particulares (SKIBNIEWSKI; GHOSH, 2009), tendo em vista que as condições e estratégias de construção variam de um projeto para outro (GEORGY; CHANG; ZHANG, 2005).

Esses desafios se manifestam na existência de vários interesses conflitantes, na fragmentação dos processos de gestão, equipes de gestão temporárias (HORSTMAN; WITTEVEEN, 2013; KAGIOGLOU; COOPER; AQUAD, 2001) e na dispersa cadeia de participantes, como proprietários, empreiteiros, arquitetos, engenheiros, fornecedores e órgãos de regulamentação, cada um deles seguindo diferentes processos de negócio e buscando objetivos distintos (SKIBNIEWSKI; GHOSH, 2009; WEGELIUS-LEHTONEN, 2001).

Assim, estabelecer sob qual ponto de vista o desempenho deve ser considerado - gestores, usuários finais, contratantes, investidores, entre outros - normalmente restringe a noção de sucesso de um projeto a resultados de curto prazo (SHENHAR; LEVY; DVIR, 1997).

Neste contexto, o presente trabalho tem por objetivo identificar as oportunidades para o aprimoramento dos sistemas de medição de desempenho na construção civil. Para esse fim, $(i)$ foi proposto um protocolo de análise de sistemas de medição de desempenho, validado por cinco especialistas na área. Com esse protocolo, (ii) foram analisados 22 modelos propostos nos últimos 25 anos, o que permitiu mapear as principais características, papéis e processos das práticas no setor. Tal diagnóstico foi expresso quantitativamente e explorado em profundidade, identificando gaps e oportunidades de melhoria, esforço que permitiu (iii) a proposição de um framework que distingue um sistema de indicadores (medir) de um sistema de medição de desempenho (medir e gerir o desempenho). Por 
fim, (iv) elaborou-se uma matriz que relaciona os papéis do sistema com seus processos, a partir da visão dos mesmos especialistas que validaram o protocolo de análise.

\section{Características, papéis e processos da medição de desempenho}

O desempenho é um conceito multifacetado que vem sendo explorado por uma variedade de campos do conhecimento como Contabilidade, Estratégia, Recursos Humanos, Produção e Gestão de Operações, Marketing, Comportamento Organizacional e Gestão Estratégica (FRANCOSANTOS; LUCIANETTI; BOURNE, 2012; NEELY, 1999).

Tal dispersão epistemológica leva a uma ampla variedade de definições encontradas na literatura.

Entretanto, note-se que, entre as várias definições encontradas, a "[...] medição como ferramenta de controle é, provavelmente, a mais conhecida e mais frequente aplicação da medição" (SINK; TUTTLE, 1993, p. 160). Por muito tempo a medição de desempenho foi compreendida como um processo estático, com o objetivo de gerar indicadores de resultados relativos a produtos ou serviços, principalmente em termos de desempenho de custos, baseados em sistemas de orçamentação tradicionais ou de custos baseados em atividades (activity-based cost) (FRANCOSANTOS; LUCIANETTI; BOURNE, 2012).

De uma perspectiva histórica, a medição de desempenho se caracterizava, em sua primeira fase, pela ênfase em medidas de desempenho financeiro e de produtividade (GHALAYINI; NOBLE, 1996). Contudo, a definição apresentada por Lebas (1995) sugere a existência de um processo de gestão cíclico, mais abrangente, composto de duas etapas:

(a) geração e coleta de indicadores de desempenho; $\mathrm{e}$

(b) gestão do desempenho.

Embora não exista sobreposição entre ambas, Bassioni, Price e Hassan (2004), corroborando a visão de Lebas (1995), argumentam que tais etapas são indissociáveis.

Como parte integrante desse processo cíclico, a medição é,

\section{[...] a base do desenvolvimento de sistemas de apoio para planejamento, solução de problemas, tomada de decisões, melhoria, controle, adaptação, motivação e até mesmo liderança. (SINK; TUTTLE, 1993. p. 159).}

Por essa pluralidade de significados e usos, Franco-Santos et al. (2007) realizaram uma análise da literatura e concluíram que uma única definição abrangente inviabilizaria a operacionalização do conceito de medição de desempenho.

Dessa forma, os autores não propuseram uma nova definição, mas sim assentaram as bases do conhecimento mapeando características, papéis e processos considerados essenciais para um sistema de medição de desempenho (SMD), conforme a Figura 1.

Figura 1 - Características, papéis e processos de um SMD

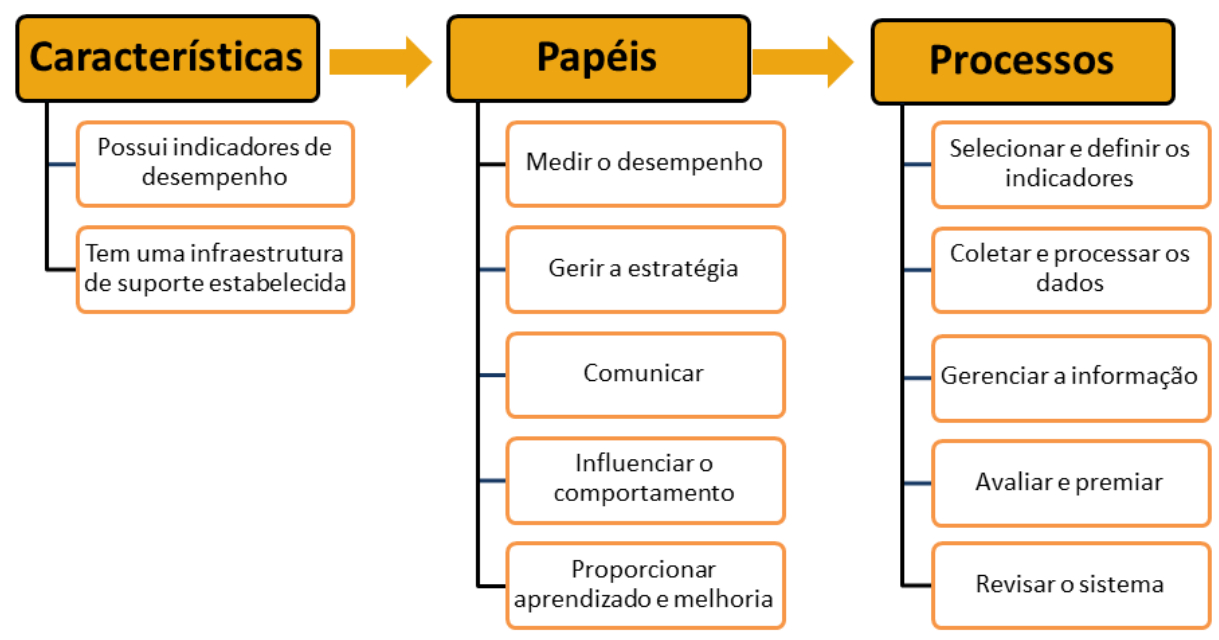

Fonte: elaborado a partir de Franco-Santos et al. (2007). 
O uso de medidas de desempenho financeiro como único parâmetro de avaliação de sucesso não era suficiente. Ademais, elas não eram capazes de refletir as mudanças nas estratégias competitivas e nas circunstâncias ambientais a que as organizações modernas passaram a ser submetidas (KENNERLEY; NEELY, 2002), o que levou várias empresas a utilizar indicadores não financeiros, como qualidade, satisfação do cliente e inovação (KAPLAN; NORTON, 1992; NUDURUPATI; ARSHAD; TURNER, 2007).

Essa perspectiva, iniciada na década de 1980, que inaugurou a segunda fase da evolução dos SMDs (GHALAYINI; NOBLE, 1996), evidenciou a inadequação dos sistemas de medição tradicionais baseados em contabilidade financeira (NEELY, 1999).

Neely e Bourne (2000) observam que, na primeira fase da medição de desempenho o problema fundamental era a medição de coisas erradas. $\mathrm{Na}$ virada do século, porém, o problema estava relacionado à obsessão das empresas em medir tudo, ou seja, a medição como um fim em si mesmo (NEELY; BOURNE, 2000).

Pode-se apontar também que grande parte das empresas ainda não consegue sequer definir o que realmente reflete suas necessidades, ou seja, o que elas de fato precisam medir. Isso permanece um desafio para pesquisadores e profissionais da área (NEELY; BOURNE, 2000), e é nesse contexto que se encontram as empresas de construção.

Costa (2003) aponta que as empresas de construção têm dificuldade de explicitar os objetivos e suas ações estratégicas, e não utilizam o planejamento estratégico para selecionar as medidas mais adequadas. Além disso, o processo de seleção se baseia na necessidade de monitoramento de atividades específicas ou na facilidade de coleta dos dados, o que pode direcionar o esforço de medição para processos menos relevantes.

Ademais, segundo Barbosa (2010), há um descompasso entre teoria e prática da medição de desempenho na construção, em que os sistemas de medição de desempenho, quando existem, apresentam graves deficiências.

A seguir, uma análise sobre a literatura de medição de desempenho na construção dá evidências que reafirmam tal descompasso entre teoria e prática e as dificuldades enfrentadas pelas organizações para definir quais indicadores são relevantes para o SMD.

\section{Medição de desempenho e seu uso na construção}

Por muito tempo a medição de desempenho na construção se limitou ao exercício do controle de custos, de prazo e de qualidade (TOOR; OGUNLANA, 2010), cuja abordagem é hoje considerada insuficiente para avaliar $\mathrm{O}$ desempenho no setor (KAGIOGLOU; COOPER; AQUAD, 2001).

Isso tem colocado empresas e pesquisadores diante de um novo desafio: medir aspectos qualitativos e intangíveis de desempenho (JIN et al., 2013). Tanto em nível organizacional como operacional, identificar corretamente os fatores críticos de sucesso de uma organização e/ou de um projeto se tornou uma questão fundamental para a gestão da construção (BASSIONI; PRICE; HASSAN, 2005; JIN et al., 2013).

Tal desafio tem estimulado a aplicação de modelos conceituais baseados no Balanced Scorecard (BSC) (BASSIONI; PRICE; HASSAN, 2004; ELMASHALEH; MINCHIN JUNIOR; O'BRIEN, 2007; KAGIOGLOU; COOPER; AQUAD, 2001; LUU et al., 2008; NUDURUPATI; ARSHAD; TURNER, 2007; YU et al., 2007), modelos baseados em qualidade (Quality-Based Performance Excellence Models), como o European Foundation for Quality Management (EFQM), o Excellence Model na Europa, o Malcolm Baldrige National Quality Award (MBNQA) nos EUA e o Deming Prize no Japão (BASSIONI; PRICE; HASSAN, 2005; BEATHAM et al., 2005; YU et al., 2007); e modelos baseados em Key Performance Indicators (KPI) (CHAN; CHAN, 2004; HORTA; CAMANHO; COSTA, 2010).

O BSC é um modelo que visa a proporcionar à alta gestão das empresas uma visão rápida e abrangente do negócio, por meio de um conjunto de medidas de desempenho que buscam relacionar aspectos qualitativos a resultados financeiros, integrando quatro perspectivas: finanças, clientes, processos internos, e inovação e aprendizado (KAPLAN; NORTON, 1992). Esse modelo tem sido utilizado como base para o desenvolvimento de medição organizacional (LUU et al., 2008) ou ainda em adaptações à realidade da construção com a incorporação de novas perspectivas, como projetistas e fornecedores (KAGIOGLOU; COOPER; AQUAD, 2001).

O EFQM Excellence Model, por seu turno, tem como objetivo proporcionar condições para que as organizações se autoavaliem por meio de oito princípios: 
(a) agregar valor para os clientes;

(b) criar um futuro sustentável;

(c) desenvolver as capacidades organizacionais;

(d) aproveitar a criatividade e a inovação;

(e) liderar com visão, inspiração e integridade;

(f) gerenciar com agilidade;

(g) decidir a sucessão por meritocracia; e

(h) sustentar excelentes resultados (THE EUROPEAN FOUNDATION FOR QUALITY MANAGEMENT, 2014).

Por fim, os modelos baseados nos KPIs consistem da seleção de um conjunto de indicadores adequado para a avaliação do desempenho organizacional, não sendo, todavia, considerados como um sistema de medição de desempenho per se. Sua utilização é popular principalmente nos clubes de benchmarking setorial cuja teoria é utilizada por várias indústrias para melhorar o desempenho do processo dos negócios e produtos (HAPONAVA; AL-JIBOURI, 2009).

A aplicação desses modelos tem permitido uma visão mais holística da natureza do desempenho. Em geral, pesquisas buscam:

(a) captar as múltiplas perspectivas do desempenho em um único parâmetro agregado (ARDITI; LEE, 2003; DENG; SMYTH, 2014; JIN et al., 2013; LUU et al., 2008; YU et al., 2007);

(b) proporcionar uma visão dinâmica de seu desempenho ao longo do tempo; e/ou

(c) prover condições para a prática de benchmarking externo (EL-MASHALEH; MINCHIN JUNIOR; O'BRIEN, 2007; HORTA; CAMANHO; COSTA, 2010; YU et al., 2007).

Entretanto, a maioria dessas estruturas para medição tem sido notadamente utilizada para a prática do benchmarking (HAPONAVA; ALJIBOURI, 2009), cujas iniciativas mais conhecidas incluem Construction Industry Institute Benchmarking and Metrics (EUA), Key Performance Indicators (Reino Unido), National
Benchmarking System for the Chilean Construction Industry (Chile) e Sistema de Indicadores de Qualidade e Produtividade na Indústria da Construção (Brasil) (COSTA et al., 2004).

Apesar dessas iniciativas, Nudurupati, Arshad e Turner (2007) e Deng, Smyth e Anvuur (2012) argumentam que ainda não é possível perceber suas contribuições como práticas consolidadas no gerenciamento da construção.

Assim, concluir que existe um modelo ideal para medição de desempenho na construção pode ser imprudente (JIN et al., 2013).

\section{Método}

Na presente pesquisa foi realizada uma análise de conteúdo (CHIZZOTI, 2011; KRIPPENDORFF, 2004) em que se avaliou o grau de aderência dos estudos da área de medição de desempenho na indústria da construção com um protocolo proposto tendo por base o framework de FrancoSantos et al. (2007). Essa análise tem caráter exploratório-descritivo e visa a ampliar o domínio de campo do conhecimento em estudo, além de permitir o surgimento de hipóteses a ser verificadas em estudos posteriores (COLLIS; HUSSEY, 2005; RICHARDSON, 2011), neste caso, acerca da medição de desempenho na indústria da construção.

A Figura 2 apresenta o delineamento da pesquisa, contendo as etapas em que ela foi realizada.

\section{Seleção dos modelos de medição de desempenho na indústria da construção}

A revisão da literatura se concentrou em analisar:

(a) trabalhos sobre medição de desempenho na indústria; e

(b) trabalhos desenvolvidos especificamente para a indústria da construção. 
Figura 2 - Delineamento da pesquisa

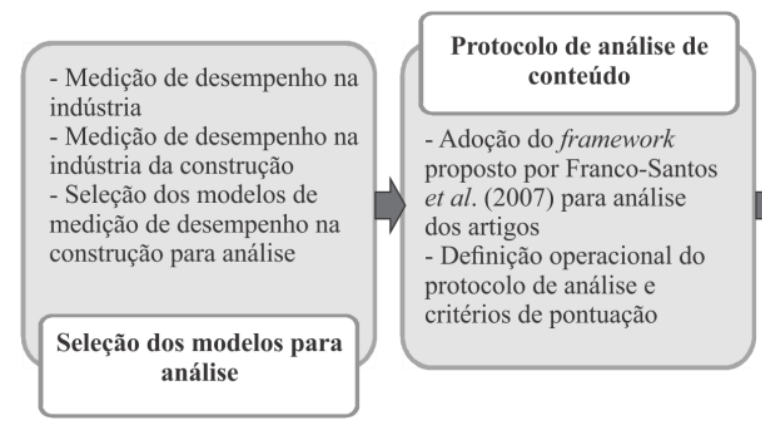

Para os trabalhos da indústria da construção foram selecionados inicialmente os dez artigos mais relevantes, conforme número de citações (via Google Acadêmico ${ }^{\circledR}$ ), a saber: Chan e Chan (2004), Kagioulou, Cooper e Aquad (2001), Bassioni, Price e Hassan (2005), WegeliusLehtonen (2001), Alarcón e Ashley (1996), Yu et al. (2007), El-Mashaleh, Minchin Junior e O'Brien (2007), Luu et al. (2008), Arditi e Lee (2003) e Nudurupati, Arshad e Turner (2007).

As referências adotadas por esses autores foram analisadas de modo a proporcionar uma visão dos principais periódicos que abordam o tema. As publicações desses periódicos também foram exploradas para os últimos cinco anos (20102014). Tal esforço gerou uma amostra com 457 trabalhos - entre artigos, teses, dissertações e notas técnicas de clubes de benchmarking. Por meio da análise dos títulos, das palavras-chave e dos resumos, foram identificados 22 trabalhos que propuseram modelos de medição, os quais foram objeto da análise de conteúdo.
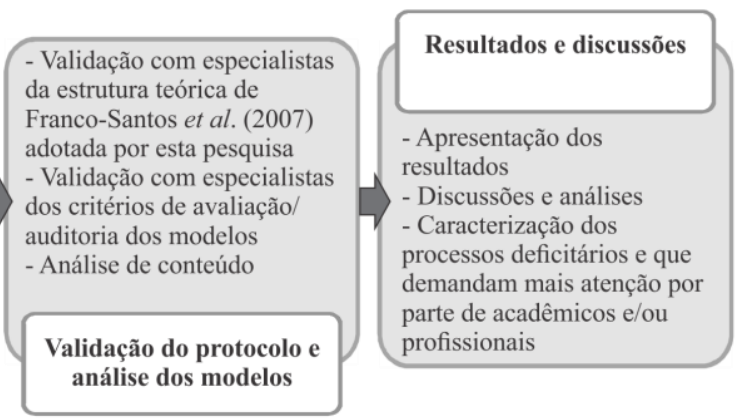

Apesar de a seleção dos modelos ter apresentado uma boa cobertura com modelos que datam de 1996 a 2014, os critérios de seleção adotados podem representar, a despeito dos esforços envidados, uma limitação metodológica (podendo outros modelos não ter sido encontrados), ainda que isso não invalide os resultados apresentados.

\section{Protocolo de análise de conteúdo}

Para os modelos selecionados foram identificadas as evidências dos aspectos considerados essenciais por Franco-Santos et al. (2007). Como estes autores não se aprofundaram na definição operacional desses aspectos, buscou-se aqui expandir tal discussão, resultando em uma definição operacional que viabilizou a análise de conteúdo.

Para essa análise foi adotada uma escala de três pontos, para avaliar a aderência dos aspectos propostos, conforme critérios apresentados no Quadro 1. 


\section{Quadro 1 - Definição operacional do protocolo de análise de conteúdo (Continua...)}

\begin{tabular}{|c|c|c|}
\hline Item & Aspectos & Critérios \\
\hline \multirow[b]{2}{*}{ 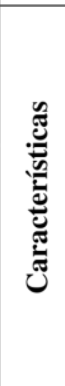 } & $\begin{array}{l}\text { Possuir } \\
\text { indicadores de } \\
\text { desempenho }\end{array}$ & $\begin{array}{l}\text { O modelo possui indicadores de desempenho vinculados à estratégia? } \\
0 \text { - O modelo não possui indicadores de desempenho } \\
1 \text { - O modelo possui indicadores de desempenho sejam eles de qualquer natureza } \\
2 \text { - O modelo possui indicadores explicitamente vinculados à estratégia da empresa }\end{array}$ \\
\hline & $\begin{array}{l}\text { Ter uma } \\
\text { infraestrutura } \\
\text { de suporte } \\
\text { estabelecida }\end{array}$ & $\begin{array}{l}\text { O modelo possui uma infraestrutura de suporte simples ou melhorada por sistema } \\
\text { informatizado? } \\
0 \text { - O modelo não apresenta uma infraestrutura de suporte } \\
1 \text { - O modelo apresenta uma infraestrutura de suporte constituído de um simples } \\
\text { método de coleta e análise de dados (uso de planilhas eletrônicas, por exemplo) } \\
2 \text { - O modelo apresenta uma infraestrutura de suporte constituído de sistema de } \\
\text { informação especializado e sofisticado }\end{array}$ \\
\hline \multirow{5}{*}{ : } & $\begin{array}{l}\text { Medir o } \\
\text { desempenho }\end{array}$ & $\begin{array}{l}\text { O modelo se propõe a medir/avaliar o desempenho e/ou acompanhar os progressos? } \\
0 \text { - O modelo não se propõe a medir/avaliar o desempenho } \\
1 \text { - O modelo se propõe a medir/avaliar o desempenho } \\
2 \text { - O modelo se propõe a acompanhar as repercussões das decisões tomadas a partir da } \\
\text { avaliação do desempenho }\end{array}$ \\
\hline & $\begin{array}{l}\text { Gerir a } \\
\text { estratégia }\end{array}$ & $\begin{array}{l}\text { O modelo se propõe a implantar/executar a estratégia e/ou manter o foco/proporcionar } \\
\text { alinhamento? } \\
0 \text { - O modelo não é utilizado para gerir a estratégia } \\
1 \text { - O modelo é utilizado para gerir a estratégia } \\
2 \text { - O modelo é utilizado para gerir a estratégia e manter o foco/proporcionar o } \\
\text { alinhamento }\end{array}$ \\
\hline & Comunicar & $\begin{array}{l}\text { O modelo propõe a comunicação interna/externa e/ou a conformidade com os } \\
\text { regulamentos e/ou a prática do benchmarking? } \\
0 \text { - O modelo não propõe a comunicação seja ela de qualquer natureza } \\
1 \text { - O modelo propõe a comunicação interna ou apenas de conformidade com } \\
\text { regulamentos } \\
2 \text { - O modelo propõe a comunicação externa ou benchmarking }\end{array}$ \\
\hline & $\begin{array}{l}\text { Influenciar o } \\
\text { comportamento }\end{array}$ & $\begin{array}{l}\text { O modelo propõe-se a premiar/recompensar as pessoas e/ou gerir/controlar os } \\
\text { relacionamentos? } \\
0 \text { - O modelo não se propõe a influenciar o comportamento } \\
1 \text { - O modelo se propõe a gerir os relacionamentos } \\
2 \text { - O modelo se propõe a premiar/recompensar as pessoas }\end{array}$ \\
\hline & $\begin{array}{l}\text { Proporcionar } \\
\text { aprendizado e } \\
\text { melhoria }\end{array}$ & $\begin{array}{l}\text { O modelo se propõe a gerar feedback e/ou proporcionar aprendizado em ciclos (double- } \\
\text { loop learning) e/ou melhoria do desempenho? } \\
0 \text { - O aprendizado não é institucionalizado } \\
1 \text { - O aprendizado é pontual e difuso } \\
2 \text { - O aprendizado é institucionalizado em ciclos (double-loop learning) de melhoria do } \\
\text { desempenho }\end{array}$ \\
\hline
\end{tabular}


Quadro 1 - Definição operacional do protocolo de análise de conteúdo (continuação...)

\begin{tabular}{|c|c|c|}
\hline Item & Aspecto & Critérios \\
\hline \multirow{5}{*}{$\sum_{\substack{n \\
:}}^{\infty}$} & $\begin{array}{l}\text { Selecionar e } \\
\text { definir os } \\
\text { indicadores }\end{array}$ & $\begin{array}{l}\text { O modelo apresenta um procedimento ou dá diretrizes para identificar, definir e } \\
\text { selecionar os indicadores? } \\
0 \text { - Não apresenta diretrizes para seleção ou definição dos indicadores } \\
1 \text { - Dá diretrizes de onde/como os indicadores devem ser selecionados (a partir da } \\
\text { estratégia, processos, dentre outros) } \\
2 \text { - Dá diretrizes de quais informações são necessárias para a operacionalização dos } \\
\text { indicadores }\end{array}$ \\
\hline & $\begin{array}{l}\text { Coletar e } \\
\text { processar os } \\
\text { dados }\end{array}$ & $\begin{array}{l}\text { O modelo apresenta um procedimento ou dá diretrizes para a criação dos dados } \\
\text { necessários, a forma com que estes são transformados em informações e como devem } \\
\text { ser apresentados para fornecer apoio à gestão? } \\
0 \text { - Não dá nenhuma diretriz } \\
1 \text { - Dá diretrizes sobre a fonte dos dados que serão utilizados e qual a ferramenta que } \\
\text { será utilizada para o procedimento } \\
2 \text { - Dá diretrizes de como deve ser a infraestrutura necessária para gerar os resultados e } \\
\text { fornecer apoio à gestão }\end{array}$ \\
\hline & $\begin{array}{l}\text { Gerenciar a } \\
\text { informação }\end{array}$ & $\begin{array}{l}\text { O modelo apresenta um procedimento ou dá diretrizes para gestão e interpretação das } \\
\text { informações conectando-as ao processo de tomada de decisão por meio da operação dos } \\
\text { mecanismos de transferência da informação (discussões, debates, publicações, } \\
\text { disseminação seletiva da informação, dentre outros, ou utilizando TICs)? } \\
0 \text { - Não dá nenhuma diretriz } \\
1 \text { - Dá diretrizes para garantir que a informação chegue aos interessados e estejam } \\
\text { disponíveis para tomada de decisão } \\
2 \text { - Dá diretrizes para garantir a integridade e a consistência dos resultados da medição, } \\
\text { bem como a forma com que estes devem ser usados (que mecanismos de transferência } \\
\text { da informação devem ser utilizados) }\end{array}$ \\
\hline & $\begin{array}{l}\text { Avaliar e } \\
\text { premiar }\end{array}$ & $\begin{array}{l}\text { O modelo apresenta um procedimento ou dá diretrizes para avaliar o desempenho e } \\
\text { recompensá-lo? } \\
0 \text { - Não existe um procedimento para avaliação e premiação de desempenho de forma } \\
\text { institucionalizada } \\
1 \text { - Existe um procedimento para avaliação de desempenho de forma institucionalizada } \\
2 \text { - Existe um sistema de recompensa que prevê incentivos para os responsáveis pelo } \\
\text { bom/mal desempenho }\end{array}$ \\
\hline & $\begin{array}{l}\text { Revisão do } \\
\text { sistema }\end{array}$ & $\begin{array}{l}\text { O modelo apresenta um procedimento ou considera a possibilidade do sistema de } \\
\text { medição ser revisado e melhorado? } \\
0 \text { - O sistema é estático, ou seja, sua revisão não é prevista } \\
1 \text { - Avalia se os indicadores ainda refletem os objetivos organizacionais } \\
2 \text { - Avalia a utilidade, eficiência e consistência do sistema como um todo }\end{array}$ \\
\hline
\end{tabular}

Fonte: elaborado a partir de Franco-Santos et al. (2007), Atkinson (1998), Barreto (2006), Bititci, Carrie e McDevitt (1997), Braglia e Frosolini (2014), Franco-Santos, Lucianetti e Bourne (2012), Kagioglou, Cooper e Aquad (2001), Kaplan e Norton (1992, 1996), Kennerley e Neely (2002), Neely e Bourne (2000), Neely, Gregory e Platts (1995), Neely et al. (2000, 1997), Sink e Tuttle (1993) e Vitale, Mavrinac e Hauser (1994).

Essa metodologia foi adaptada de estudo com objetivo similar, realizado por Deng, Smyth e Anvuur (2012). Todavia, estes autores não utilizaram nenhuma pontuação, restringindo-se a apontar se os aspectos do modelo em análise foram completamente, parcialmente ou não foram mencionados. Assim, a atribuição de uma nota para cada aspecto conferiu maior objetividade à avaliação dos modelos mapeados.

Para validação do modelo proposto, quinze especialistas no tema foram consultados por questionário via $e$-mail. O critério para escolha dos especialistas foi a participação em bancas de mestrado e/ou doutorado que tratavam do assunto, além de ter publicações na área. Os respondentes são professores com titulação de doutor (ou PhD) com mais de vinte anos de atuação em docência e pesquisa. Quando inquiridos sobre o grau de conhecimento/familiaridade em relação ao tema de medição de desempenho, apenas um respondente deu nota nove, enquanto os demais se autoavaliaram com nota dez.

Foram questionados, ainda, sobre $(i)$ a validade da estrutura conceitual adotada (framework proposto por Franco-Santos et al. (2007), referido na Figura 1) e sobre (ii) a definição operacional e a escala do protocolo de análise de conteúdo. Apenas cinco dos quinze especialistas responderam ao questionário e atribuíram uma nota em uma escala de um a cinco, bem como criticaram livremente a proposta. Os resultados desse processo são apresentados no Quadro 2. 
Quadro 2 - Resultado da validação por parte dos especialistas

\begin{tabular}{|c|c|c|c|c|c|c|c|c|c|c|c|c|}
\hline \multirow{2}{*}{$\begin{array}{l}\text { Características, papéis e } \\
\text { processos essenciais }\end{array}$} & \multicolumn{6}{|c|}{ Validade da estrutura conceitual adotada } & \multicolumn{6}{|c|}{$\begin{array}{l}\text { Definição operacional e escala do protocolo de } \\
\text { análise de conteúdo }\end{array}$} \\
\hline & \begin{tabular}{|c|} 
Grau de \\
aceitacão
\end{tabular} & Esp. 1 & Esp. 2 & Esp. 3 & Esp. 4 & Esp. 5 & \begin{tabular}{|c|} 
Grau de \\
aceitacão
\end{tabular} & Esp. 1 & Esp. 2 & Esp. 3 & Esp. 4 & Esp. 5 \\
\hline A. Características & $94 \%$ & $90 \%$ & $100 \%$ & $90 \%$ & $90 \%$ & $100 \%$ & $76 \%$ & $50 \%$ & $100 \%$ & $70 \%$ & $90 \%$ & $70 \%$ \\
\hline $\begin{array}{l}\text { a. Possuir indicadores de } \\
\text { desempenho }\end{array}$ & $96 \%$ & 5 & 5 & 4 & 5 & 5 & $68 \%$ & 2 & 5 & 2 & 5 & 3 \\
\hline $\begin{array}{l}\text { b. Ter uma infraestrutura de } \\
\text { suporte estabelecida }\end{array}$ & $92 \%$ & 4 & 5 & 5 & 4 & 5 & $84 \%$ & 3 & 5 & 5 & 4 & 4 \\
\hline B. Papéis & $94 \%$ & $92 \%$ & $100 \%$ & $80 \%$ & $100 \%$ & $100 \%$ & $77 \%$ & $64 \%$ & $68 \%$ & $76 \%$ & $92 \%$ & $84 \%$ \\
\hline a. Medir o desempenho & $100 \%$ & 5 & 5 & 5 & 5 & 5 & $92 \%$ & 4 & 5 & 4 & 5 & 5 \\
\hline b. Gerir a estratégia & $88 \%$ & 4 & 5 & 3 & 5 & 5 & $80 \%$ & 4 & 3 & 5 & 5 & 3 \\
\hline c. Comunicar & $100 \%$ & 5 & 5 & 5 & 5 & 5 & $72 \%$ & 2 & 3 & 4 & 5 & 4 \\
\hline d. Influenciar o comportamento & $88 \%$ & 4 & 5 & 3 & 5 & 5 & $56 \%$ & 2 & 3 & 2 & 3 & 4 \\
\hline $\begin{array}{l}\text { e. Proporcionar aprendizado e } \\
\text { melhoria }\end{array}$ & $96 \%$ & 5 & 5 & 4 & 5 & 5 & $84 \%$ & 4 & 3 & 4 & 5 & 5 \\
\hline C. Processos & $87 \%$ & $88 \%$ & $100 \%$ & $80 \%$ & $84 \%$ & $84 \%$ & $84 \%$ & $80 \%$ & $92 \%$ & $72 \%$ & $80 \%$ & $96 \%$ \\
\hline $\begin{array}{l}\text { a. Definir e selecionar os } \\
\text { indicadores }\end{array}$ & $100 \%$ & 5 & 5 & 5 & 5 & 5 & $88 \%$ & 5 & 3 & 4 & 5 & 5 \\
\hline d. Coletar e processar os dados & $100 \%$ & 5 & 5 & 5 & 5 & 5 & $84 \%$ & 3 & 5 & 4 & 4 & 5 \\
\hline c. Gerenciar a informação & $80 \%$ & 4 & 5 & 3 & 4 & 4 & $84 \%$ & 4 & 5 & 3 & 4 & 5 \\
\hline d. Avaliar e premiar & $80 \%$ & 4 & 5 & 4 & 3 & 4 & $80 \%$ & 4 & 5 & 4 & 3 & 4 \\
\hline e. Revisão sistemática & $76 \%$ & 4 & 5 & 3 & 4 & 3 & $84 \%$ & 4 & 5 & 3 & 4 & 5 \\
\hline Avaliação Geral & $91 \%$ & $90 \%$ & $100 \%$ & $82 \%$ & $92 \%$ & $93 \%$ & $80 \%$ & $68 \%$ & $83 \%$ & $73 \%$ & $87 \%$ & $87 \%$ \\
\hline
\end{tabular}

Observa-se que a estrutura conceitual adotada teve alto grau de aceitação (91\%), enquanto a definição operacional e a escala do protocolo de análise de conteúdo obtiveram razoável avaliação $(80 \%)$. Esses resultados foram considerados satisfatórios, uma vez que os especialistas não ofertaram nenhuma mudança radical em suas críticas, e sim complementaram os requisitos, propondo melhorias na explicitação da proposta.

Algumas controvérsias também foram observadas, como, por exemplo, a necessidade de maior detalhamento da escala de pontuações para alguns itens, como observa o Especialista 1, quando de sua crítica para o papel Comunicar: "Este item engloba muitas coisas. Merece mais de um item (Questionário 1, Especialista 1)". No outro sentido, o Especialista 3 apontou como ponto positiva a simplicidade da escala de três pontos: “[...] o sistema de pontuação em 3 níveis é simples, cristalino, cortante, sem propiciar enrolação (Questionário 3, Especialista 3)".

A adoção da escala de três pontos visou justamente à elaboração de um instrumento simples para que as empresas construtoras possam se autoavaliar e melhorar seus sistemas. A seguir são apresentados os resultados da análise dos 22 modelos com a utilização do protocolo validado.

\section{Resultados e discussões}

Inicialmente, as características gerais dos modelos de medição foram analisadas, conforme o Apêndice A.

Pode-se destacar a ampla utilização da sistemática do Balanced Scorecard como base para o desenvolvimento dos modelos propostos (36\%, ou 8 modelos), corroborando os dados apresentados por Robinson et al. (2005). Isso indica que há uma crescente preocupação de incorporar elementos de gestão estratégica na concepção dos sistemas de medição. Nesse sentido, 59\% dos modelos (12) possuem vinculação explícita entre os indicadores e a estratégia.

Em relação às dimensões de desempenho (framework estrutural), observa-se uma grande variedade de dimensões. Porém, o framework estrutural que chama a atenção foi proposto por Bassioni, Price e Hassan (2005). Este modelo, fundamentado no BSC e no EFQM, divide as dimensões de desempenho em:

(a) desempenho do empreendimento/produção/ eficiência da gestão do projeto;

(b) desempenho organizacional;

(c) desempenho dos stakeholders internos (ou seja, que estão diretamente sob a influência da organização); e 
(d) desempenho para os stakeholders externos (ou seja, que não estão diretamente sob a influência da organização).

Quanto ao framework processual, destaca-se o modelo proposto por Beatham et al. (2005), que, além de dar diretrizes para a concepção do sistema, também apresenta diretrizes para sua implantação por meio de dois ciclos:

(a) implantação das medidas; e

(b) mudanças impulsionadas pelos resultados.

Quanto à abrangência dos sistemas, observa-se primeiramente que o foco intraorganizacional se dá em diferentes níveis de análise, que vão desde o desempenho da organização e do empreendimento até processos específicos. Observa-se também uma mudança desse foco, seguindo a evolução na medição de desempenho, por meio da consideração de aspectos externos à empresa, uma perspectiva interorganizacional (FOLAN; BROWNE, 2005). As empresas começaram a se preocupar não apenas com aspectos financeiros e não financeiros, mas também com aspectos externos à organização, como mercado e fornecedores.
A seguir são discutidos os resultados da análise de conteúdo, apresentados no Fehler! Verweisquelle konnte nicht gefunden werden.

Em relação às características observa-se que o pressuposto básico para a existência de um sistema de medição de desempenho foi atendido por todos os modelos (possuir indicadores de desempenho). No entanto, pouco se discutiu sobre a infraestrutura necessária para sua operacionalização (apenas 52\%).

No tocante aos papéis que o SMD cumpre, destaca-se o uso para avaliação do desempenho (93\%), seguido da comunicação (77\%), aprendizado e melhoria $(68 \%)$ e gerência da estratégia $(57 \%)$. Verifica-se, no entanto, a escassez do uso do SMD para influenciar o comportamento $(25 \%)$.

Quanto aos processos, verifica-se que os mais bem estabelecidos são a definição e seleção dos indicadores de desempenho $(75 \%)$ e a coleta e processamento dos dados $(61 \%)$. Os demais processos ficaram abaixo de $50 \%$, com avaliar e premiar $(39 \%)$, gerenciar a informação $(32 \%)$ e revisar o sistema (23\%), indicando potenciais deficiências e, consequentemente, demandas de pesquisas.

Quadro 3 - Resultado da análise de congruência

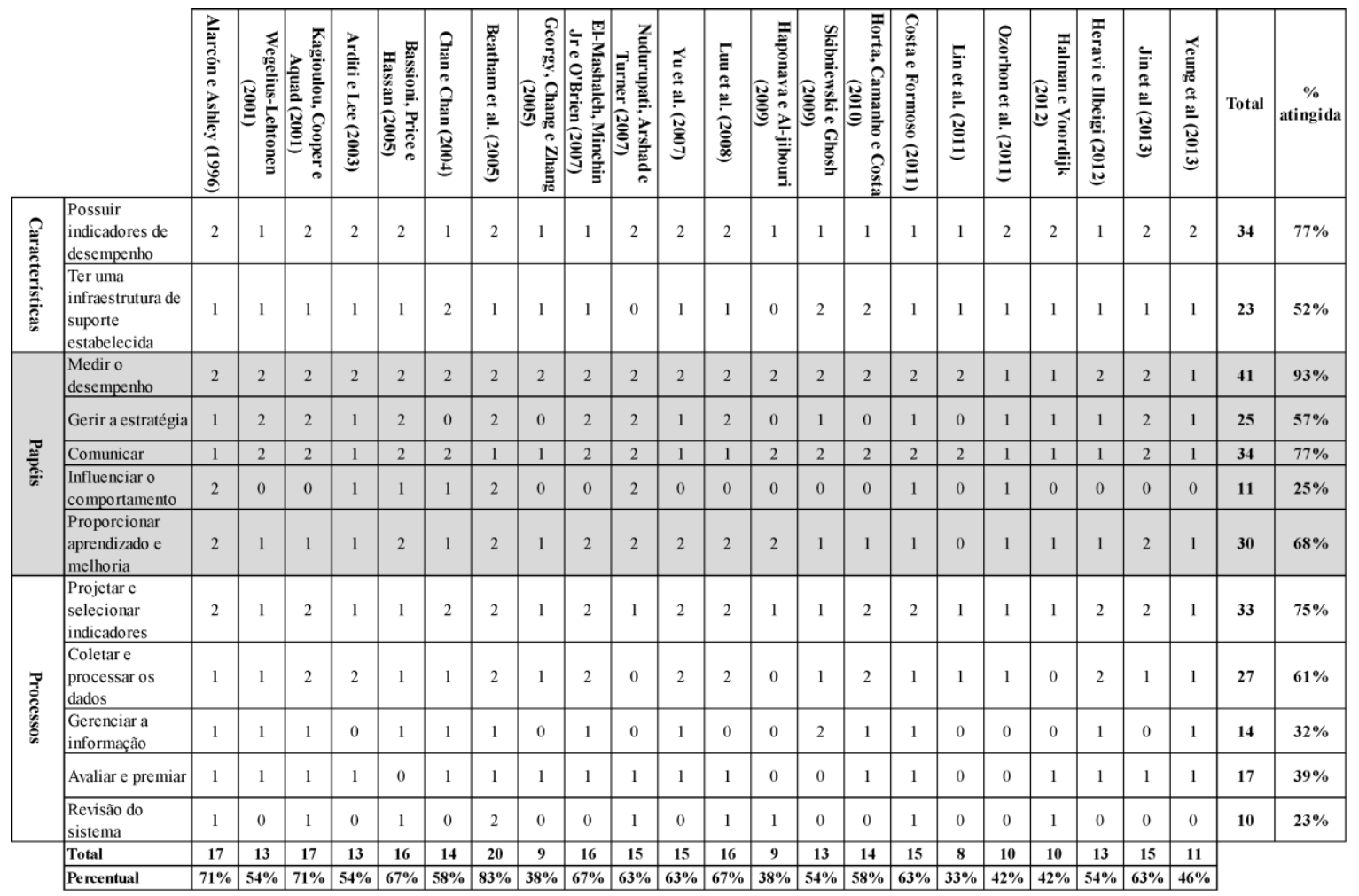

198 Cândido, L. F.; Lima, S. H. De O.; Barros Neto, J. de P. 
Em relação à seleção dos indicadores, foram identificadas três alternativas em que as empresas podem iniciar a seleção de seus indicadores:

(a) a partir da própria estratégia (36\%);

(b) a partir de clubes de benchmarking (23\%);

(c) a partir da necessidade de monitoramento de processos específicos $(23 \%)$; e

(d) a partir da literatura científica (18\%), conforme a coluna Indicadores Específicos do Quadro 5, que se encontra no Apêndice A.

Apesar de Costa (2003) ter apontado que as empresas de construção têm dificuldade de explicitar os objetivos e suas ações estratégicas e não utilizam o planejamento estratégico para selecionar as medidas mais adequadas, verifica-se que o principal input para definição e seleção de indicadores é a estratégia do negócio.

Em relação à definição dos indicadores, aponta-se que aquela apresentada por Neely et al. (1997), e recomendada por Kagioglou, Cooper e Aquad (2001), é a mais bem estruturada e pode ser utilizada como referência pela indústria da construção, uma vez que congrega todas as informações propostas nos demais modelos. O referido modelo apresenta catorze itens para definição das informações necessárias para a operacionalização dos indicadores:

(1) título;

(2) objetivo da medida;

(3) relação com os objetivos;

(4) meta;

(5) fórmula;

(6) frequência de medição;

(7) frequência de revisão;

(8) responsável pela coleta;

(9) fonte dos dados;

(10) encarregado;

(11) o que ele deve fazer;

(12) quem atua sobre os dados;

(13) o que ele deve fazer; e

(14) observações e comentários.

Quanto à coleta e o processamento dos dados, $14 \%$ dos modelos não apresentam qualquer diretriz para coleta e processamento, $50 \%$ dão diretrizes sobre a fonte dos dados que serão utilizados, e apenas $36 \%$ apresentam diretrizes da infraestrutura necessária para gerar os resultados e fornecer apoio à gestão.
Essa constatação merece relevo porque a efetividade da coleta e do processamento está diretamente ligada à infraestrutura para sua operacionalização. Caso ela não seja adequada, o sistema de medição de desempenho pode se tornar improdutivo, devido ao tempo, esforço e necessidade de recursos que ele demanda, conforme já observado por Neely e Bourne (2000). Nesse sentido, para tornar os SMDs mais eficientes, são adotadas ferramentas de tecnologia da informação que vão desde o uso de uma planilha simples até sistemas de informações mais sofisticados (FRANCO-SANTOS et al., 2007).

Em relação ao gerenciamento da informação, observa-se que os trabalhos se limitam a mencionar que o sistema deve possuir esse processo, porém não apresentaram diretrizes para sua operacionalização. Diferentemente da coleta e do processamento, que estão mais ligados à infraestrutura e ao suporte necessário para geração da informação, o gerenciamento da informação está relacionado ao uso da informação em si. Essa etapa envolve a manutenção do sistema de feedbacks garantindo que a informação chegue a seu destinatário e que a interpretação e a tomada de decisão sejam realizadas (FRANCO-SANTOS et al., 2007).

Verificou-se que $41 \%$ dos trabalhos nem mesmo apresentam diretrizes para esse processo e que $55 \%$ dão diretrizes apenas para garantir que a informação chegue aos interessados e esteja disponível para a tomada de decisão. Vale destacar que apenas o trabalho de Skibniewski e Ghosh (2009) empreendeu uma análise mais aprofundada para esta etapa, apresentando um fluxograma multifuncional para coleta de dados e informações para empresas de construção, o que aumentou a garantia de que as informações geradas serão entregues aos interessados em tempo hábil para a tomada de decisão. Constatou-se, por fim, que o principal mecanismo para transferência da informação utilizado foram os clubes de benchmarking.

Com relação ao processo de avaliação e premiação do SMD, obteve-se 39\% de aderência, valendo salientar que nenhum dos modelos indicou a existência de um sistema de recompensas que prevê incentivos para os responsáveis pelo bom desempenho, limitando-se a diretrizes para a avaliação do desempenho. Armstrong e Brown (2009) apontam que a prática da avaliação e premiação é um ponto-cego e crítico para várias empresas que possuem sistema de recompensa. É uma dificuldade iminente aos gestores, pois existem poucas evidências concretas para analisar ou justificar as práticas de premiação. 
Sink e Tuttle (1993) asseveram que tais condições induzem os funcionários a focar na produção de um bom indicador (meios), em detrimento de gerar valor para empresa (fins). Portanto, a avaliação e a premiação não devem ser compreendidas apenas como controle ou ter caráter meramente punitivo, mas sim, como defendem Neely, Gregory e Platts (1995), devem ser compatíveis com a cultura organizacional, proporcionando transparência e incentivos à melhoria contínua.

A revisão do sistema foi o processo que apresentou pior pontuação $(23 \%)$, mostrando-se questão crítica, uma vez que o SMD deve ser flexível para incorporar as mudanças do mercado. Observou-se que os modelos não possuem uma sistemática estruturada para que os usuários avaliem a qualidade do sistema e seu alinhamento aos objetivos. Trinta e seis por cento dos modelos preveem uma revisão periódica apenas dos indicadores, ou seja, avaliam se os indicadores ainda refletem os objetivos organizacionais. Porém, a utilidade, a eficiência e a consistência do sistema como um todo têm sido pouco exploradas, valendo observar que apenas o trabalho de Beatham et al. (2005) prevê esta análise.

Pode-se destacar também a natureza dinâmica do modelo proposto por Alarcón e Ashley (1996). Os autores combinam fatores internos à empresa, conhecimentos da gerência do projeto e de suas características técnicas para direcionar o SMD, a cada novo projeto ou empreendimento.

Por fim, em consequência do processo de análise empreendido na pesquisa, notou-se a congruência entre a visão de Lebas (1995) - que distinguiu a medição de desempenho da gestão de desempenho
- e os processos considerados essenciais do framework proposto Franco-Santos et al. (2007).

Nesse sentido, um dos achados deste estudo postula que as visões são complementares e que ajudam a dissociar o que Lebas (1995) chama de "medir o desempenho" e "gerir o desempenho". Argumenta-se, portanto, que a gestão de desempenho vista por Lebas (1995) pode ser alcançada naturalmente com o estabelecimento dos processos ditos essenciais por Franco-Santos et al. (2007).

Assevera-se, além disso, que selecionar, definir, coletar e processar são processos típicos de sistemas de indicadores de desempenho, o que não pode ser confundido com sistema de medição de desempenho, uma vez que este compreende também os processos de gerenciamento da informação, avaliação e premiação, e a rotina de revisão do sistema, conforme a Figura 3.

Essa dissociação permitiu ainda uma reflexão sobre o uso dos sistemas de medição de desempenho. Percebeu-se que o estabelecimento dos processos deve estar vinculado a seus papéis. Assim, quais processos devem estar bem estabelecidos caso a empresa deseje apenas gerar indicadores? E caso ela deseje gerenciar sua estratégia?

Para responder a esses questionamentos, elaborouse uma matriz que relaciona os papéis do sistema com seus processos a partir da visão dos mesmos especialistas que validaram o protocolo de análise de conteúdo. Os respondentes atribuíram nota de 1 a 5 avaliando o impacto que cada processo tem sobre os papéis que o sistema se propõe a cumprir. A matriz resultante é apresentada no Quadro 4.

Figura 3 - Componentes e processos da medição de desempenho

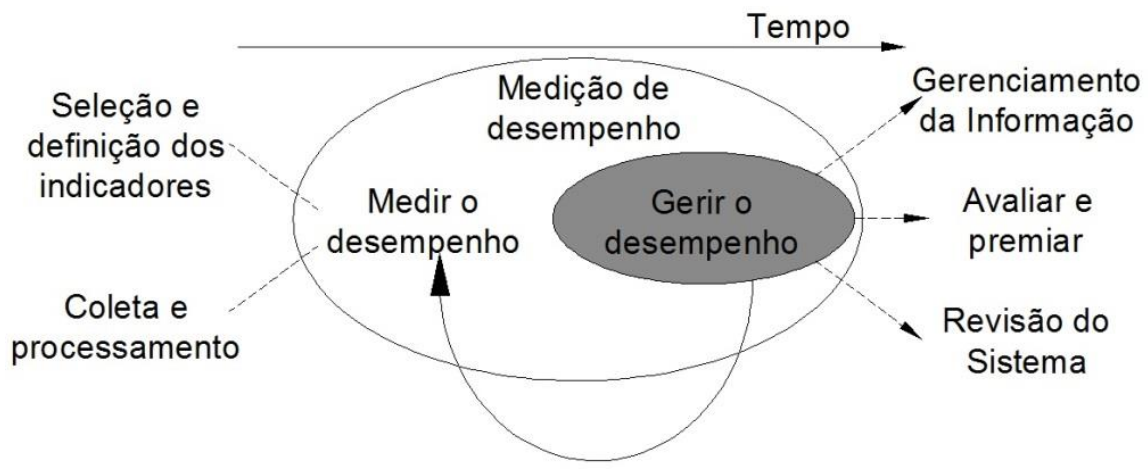

Fonte: adaptado de Lebas (1995) e Franco-Santos et al. (2007). 


\section{Quadro 4 - Relações entre os usos e os processos do SMD}

\begin{tabular}{|c|c|c|c|c|c|c|}
\hline & \multicolumn{5}{|c|}{ Processos } \\
\hline & & $\begin{array}{c}\text { a. Definir e } \\
\text { selecionar os } \\
\text { indicadores }\end{array}$ & $\begin{array}{c}\text { b. Coletar e } \\
\text { processar os } \\
\text { dados }\end{array}$ & $\begin{array}{l}\text { c. Gerenciar a } \\
\text { informação }\end{array}$ & $\begin{array}{l}\text { d. Avaliar e } \\
\text { premiar }\end{array}$ & $\begin{array}{l}\text { e. Revisão } \\
\text { sistemática }\end{array}$ \\
\hline \multirow{5}{*}{ 这 } & a. Medir o desempenho & $80 \%$ & $100 \%$ & $92 \%$ & $64 \%$ & $80 \%$ \\
\hline & b. Gerir a estratégia & $96 \%$ & $92 \%$ & $96 \%$ & $68 \%$ & $76 \%$ \\
\hline & c. Comunicar & $92 \%$ & $92 \%$ & $96 \%$ & $56 \%$ & $56 \%$ \\
\hline & $\begin{array}{l}\text { d. Influenciar o } \\
\text { comportamento }\end{array}$ & $96 \%$ & $84 \%$ & $92 \%$ & $92 \%$ & $76 \%$ \\
\hline & $\begin{array}{l}\text { e. Proporcionar } \\
\text { aprendizado e melhoria }\end{array}$ & $96 \%$ & $88 \%$ & $100 \%$ & $84 \%$ & $76 \%$ \\
\hline
\end{tabular}

Observa-se que, de modo geral, os processos têm alto grau de influência para os papéis, destacandose apenas o baixo grau de impacto da avaliação e premiação e a revisão sistemática para a comunicação. Essa constatação é interessante: uma vez que o sistema produz informações, estas devem ser entregues naturalmente a seus destinatários; estes podem ou não utilizá-las para avaliação e premiação. Ademais, parte-se do pressuposto de que essas informações foram comunicadas porque estão corretas e/ou refletem os objetivos da empresa.

De maneira semelhante, avaliar e premiar têm baixo impacto no uso do sistema para medir o desempenho. Essa constatação também parece lógica, pois medir o desempenho é o primeiro passo do sistema; além disso, mais importante que medir é o uso dessa informação que perpassa os outros papéis essenciais do sistema de medição.

Assim, pode-se pontuar que para medir o desempenho apenas o processo de avaliação e premiação tem pouca influência. Para gerir a estratégia, no entanto, praticamente todos os processos devem estar bem estabelecidos. Já para a comunicação é fundamental definir e selecionar adequadamente os indicadores, coletar e processálos, e gerenciar a informação gerada. Para influenciar o comportamento e proporcionar aprendizado e melhoria, apenas a revisão sistemática foi avaliada com grau de impacto mediano.

Esse resultado indica que, independentemente de (i) o sistema possuir indicadores vinculados à estratégia da empresa, (ii) suas metas estarem desajustadas, ou (iii) o procedimento de operacionalizar os indicadores seja difícil e demorado (requisitos da revisão sistemática), as pessoas estarão sob a influência dos resultados apresentados pelo sistema de medição de desempenho. A questão é, nesse sentido, como esses resultados serão utilizados. Em outras palavras, o indicador poderá ser um ponto de partida para mudança e melhoria, ou ter meramente caráter de controle, ou, ainda mais grave, que este controle assuma um viés punitivo.

Observa-se ainda que todos os aspectos contidos nas características, papéis e processos do protocolo proposto têm o mesmo peso para a apuração do total de pontos e percentuais atingidos. $\mathrm{Na}$ realidade prática, alguns aspectos podem ser mais relevantes - peso maior - para promover a eficácia do SMD, e a relação explorada no Quadro 4 sugere que há um conjunto de processos para um conjunto de papéis desejáveis, embora sua distinção ainda não seja clara (tendo em conta que os especialistas manifestaram dificuldades para sua explicitação).

A depuração desses pesos pode ser alcançada com a aplicação do protocolo em casos reais ou com uma amostra mais abrangente de especialistas, incluindo rodadas de debate ou adotando o método Delphi para uma proposição mais consistente de coeficientes, o que não fez parte do escopo deste trabalho.

Com a matriz de relações entre os usos e os processos, as empresas podem verificar se seus sistemas de medição de desempenho (SMD) são capazes de suportar o uso para o qual foram designados. Podem ainda avaliar se o sistema está robusto demais para o uso desejado, ou seja, se o SMD possui processos que vão além do uso para o qual ele foi designado. Essa clara noção pode evitar gastos desnecessários ou processos demasiados, que acabam por tornar a medição de desempenho um oneroso processo burocrático, e não uma eficiente ferramenta de apoio à gestão.

\section{Considerações finais}

O presente trabalho teve por objetivo identificar as oportunidades para o aprimoramento dos sistemas de medição de desempenho na construção civil. Para tal, primeiramente se estabeleceu um processo de avaliação quantificável para avaliar características, papéis e processos essenciais, 
baseados no framework proposto por FrancoSantos et al. (2007). Esse processo de avaliação foi validado por especialistas da área e constitui a primeira contribuição ao campo, pois pode ser utilizado como instrumento de auditoria dos sistemas de medição estabelecidos nas organizações.

De posse desse instrumento, foram analisados os 22 modelos de medição de desempenho, sendo possível diagnosticar as principais práticas ainda não estabelecidas, a que se atribui a segunda contribuição deste estudo. Tal diagnóstico foi expresso quantitativamente e explorado em profundidade, apontando-se caminhos e identificando-se gaps e oportunidades de melhoria, que suscitam profícua agenda para futuras pesquisas.

Este diagnóstico permitiu tornar evidente a fragilidade dos atuais modelos, principalmente no tangente ao papel de influenciar o comportamento das pessoas na organização, bem como aos processos de gerenciamento da informação, implantação de incentivos e adaptação dos sistemas às pressões de mercado e às condições de cada novo projeto.

A proposição de um framework que soma as visões de Lebas (1995) e de Franco-Santos et al. (2007) proporciona uma visão mais completa do processo de medição, ressaltando a diferença entre sistema de indicadores (geração e coleta de indicadores) e sistema de medição de desempenho (geração, coleta de indicadores e gestão do desempenho). Este framework designa o norte onde se pretende chegar em termos de sistemas de medição de desempenho.

Por fim, explorou-se a relação entre os papéis que o sistema se propõe a desempenhar e os processos que precisam ser executados. Tal relação sugere que há um conjunto de processos para um conjunto de papéis desejáveis, embora sua distinção ainda não seja explicita e clara, ou seja, os especialistas manifestaram dificuldades para sua explicitação.

Por meio desta análise, as empresas podem verificar se seus SMDs são capazes de suportar o uso para o qual foram designados. Podem ainda avaliar se o sistema está robusto demais para o uso desejado. Essa clara noção pode evitar gastos desnecessários ou processos demasiados, que acabam por tornar a medição de desempenho um oneroso processo burocrático, e não uma eficiente ferramenta de apoio à gestão.

Conclui-se que, apesar das inúmeras iniciativas de melhoria analisadas, a indústria da construção ainda necessita de modelos de medição que ofereçam diretrizes operacionais mais contundentes. Se a evolução dos sistemas de medição de desempenho na construção é lenta, como argumentam Deng, Smyth e Anvuur (2012), alguns dos aspectos que confirmam essa deficiência foram mapeados, podendo, portanto, ser aprimorados e discutidos no ambiente acadêmico e empresarial.

Para a melhoria dos processos em si, sugere-se como agenda de pesquisas:

(a) explorar o processamento dos dados, ou seja, a infraestrutura necessária para gerar os resultados e fornecer apoio à gestão. A não integração do processamento na rotina da empresa torna o SMD ineficaz. Investir em TI pode ser um caminho para esse processo, mas deve-se atentar para a flexibilidade do sistema, ou seja, sua capacidade de atualização, uma vez que as empresas atuam em um ambiente turbulento e de rápidas mudanças;

(b) devem-se empreender esforços, também, para a melhoria da gestão da informação. Não basta garantir que a informação esteja disponível e chegue aos destinatários. É necessário que a informação seja transformada em conhecimento, habilitando aos gestores melhor utilizá-las para a tomada de decisão;

(c) são necessárias melhorias na conexão da avaliação com um sistema de recompensas, pois nenhum dos modelos indicou a existência de um sistema de recompensas. Observou-se que essa temática é bastante discutida na literatura de Recursos Humanos, e um caminho para a melhoria desse processo pode ser encontrado nessa literatura específica. Pode-se apontar como prolífica fonte de trabalhos o Compensation and Benefits Review (Comentários sobre compensações e benefícios) e o European Reward Management Conference (Conferência Europeia de Gestão de Recompensas); e

(d) deve-se dedicar atenção para o processo de revisão sistemática do sistema quanto a sua utilidade, eficiência e consistência como um todo, e não apenas de seus indicadores individualmente. Isso pode garantir que o sistema esteja atualizado e com plenas condições de uso.

Recomenda-se ainda a aplicação do protocolo como um instrumento de auditoria em empresas construtoras para verificar sua utilidade, qualidade e eficácia. Também não se discutiu a observância aos aspectos avaliados em um cenário de implantação de um SMD, o que seria oportuno em pesquisas de caráter mais prático, como pesquisaação ou design science research. 


\section{Referências}

ALARCÓN, L. F.; ASHLEY, D. B. Modeling Project Performance for Decision Making. Journal of Construction Engineering and Management, v. 122, n. 3, p. 265-273, 1996.

ARDITI, D.; LEE, D. E. Assessing the Corporate Service Quality Performance of Design-Build Contractors Using Quality Function Deployment. Construction Management and Economics, v. 21, n. 2, p. 175-185, 2003.

ARMSTRONG, M.; BROWN, D. Increasing the Effectiveness of Reward Management. In: EUROPEAN REWARD MANAGEMENT CONFERENCE, 2., Brussels, 2009.

Anais...Brussels: EIASM, 2009.

ATKINSON, A. Strategic Performance Measurement and Incentive Compensation. European Management Journal, v. 16, n. 5, p. 552-561, 1998.

BARBOSA, A. S. Uso de Indicadores de Desempenho nas empresas construtoras brasileiras: diagnóstico e orientações para utilização. São Carlos, 2010. 273 f. Tese (Doutorado em Engenharia de Produção) - Escola de Engenharia, Universidade de São Paulo, São Carlos, 2010.

BARRETO, A. M. Gestão da Informação: ferramenta da produção ou da significação? Informação \& Sociedade: Estudos, v. 16, n. 2, p. 51-61, 2006.

BASSIONI, H. A.; PRICE, A. D. F.; HASSAN, T. M. Building a Conceptual Framework for Measuring Business Performance in Construction: an empirical evaluation. Construction

Management and Economics, v. 23, n. 5, p. 495507, 2005.

BASSIONI, H. A.; PRICE, A. D. F.; HASSAN, T. M. Performance Measurement in Construction. Journal of Management in Engineering, v. 20, n. 2, p. 42-50, 2004.

BEATHAM, S. et al. An Integrated Business Improvement System (IBIS) For Construction. Measuring Business Excellence, v. 9, n. 2, p. 4255, 2005.

BITITCI, U. S.; CARRIE, A. S.; MCDEVITT, L. Integrated Performance Measurement Systems: an audit and development guide. The TQM

Magazine, v. 9, n. 1, p. 46-53, 1997.

BRAGLIA, M.; FROSOLINI, M. An Integrated Approach to Implement Project Management Information Systems within the Extended Enterprise. International Journal of Project Management, v. 32, n. 1, p. 18-29, 2014.
CHAN, A. P. C.; CHAN, A. P. L. Key

Performance Indicators for Measuring

Construction Success. Benchmarking: An

International Journal, v. 11, n. 2, p. 203-221, 2004.

CHIZZOTI, A. Pesquisa Qualitativa em Ciências Humanas e Sociais. 6. ed. Petrópolis: Vozes, 2011.

COLLIS, J.; HUSSEY, R. Pesquisa em

Administraçao: um guia prático para alunos de graduação e pós-graduaçao. 2. ed. Porto Alegre: Bookman, 2005.

COOKE-DAVIES, T. The "Real" Success Factors on Projects. International Journal of Project Management, v. 20, n. 3, p. 185-190, 2002.

COSTA, D. B. Diretrizes Para Concepção, Implementação e Uso de Sistemas de Indicadores de Desempenho Para Empresas da Construção Civil. Porto Alegre, 2003. 176 f. Dissertação (Mestrado em Engenharia Civil) Programa de Pós-graduação em Engenharia Civil, Universidade Federal do Rio Grande do Sul, Porto Alegre, 2003.

COSTA, D. B. et al. Performance Measurement Systems for Benchmarking In the Construction Industry. In: ANNUAL CONFERENCE OF THE INTERNATIONAL GROUP FOR LEAN CONSTRUCTION, 12., Copenhaguen, 2004. Anais...Copenhaguen: IGLC, 2004.

DENG, F.; SMYTH, H. Nature of Firm Performance in Construction. Journal of Construction Engineering and Management, v. 140, n. 2, 2014.

DENG, F.; SMYTH, H.; ANVUUR, A. A critical Review of PMS in Construction: towards a research agenda. In: ANNUAL ARCOM CONFERENCE, 28., Edinburgh, 2012. Anais.. Edinburgh: ARCOM, 2012.

EL-MASHALEH, M. S.; MINCHIN JUNIOR, R. E.; O'BRIEN, W. J. Management of Construction Firm Performance Using Benchmarking. Journal of Management in Engineering, v. 23, n. 1, p. 10-17, 2007.

FOLAN, P.; BROWNE, J. A Review of Performance Measurement: towards performance management. Computers in Industry, v. 56, n. 7, p. $663-680$, set. 2005

FRANCO-SANTOS, M. et al. Towards a Definition of a Business Performance Measurement System. International Journal of Operations \& Production Management, v. 27, n. 8, p. 784-801, 2007. 
FRANCO-SANTOS, M.; LUCIANETTI, L.; BOURNE, M. Contemporary Performance Measurement Systems: a review of their consequences and a framework for research.

Management Accounting Research, v. 23, n. 2, p. 79-119, 2012.

GEORGY, M. E.; CHANG, L.-M.; ZHANG, L. Utility-Function Model for Engineering Performance Assessment. Journal of Construction Engineering and Management, v. 131, n. 5, p. 558-568, 2005.

GHALAYINI, A. M.; NOBLE, J. S. The Changing Basis of Performance Measurement. International Journal of Operations \& Production

Management, v. 16, n. 8, p. 63-80, 1996.

GONZÁLEZ, P. et al. Analysis of Causes of Delay and Time Performance in Construction Projects. Journal of Construction Engineering and Management, v. 140, p. 1-9, 2014.

HAPONAVA, T.; AL-JIBOURI, S. Identifying Key Performance Indicators For Use in Control of Pre-Project Stage Process in Construction. International Journal of Productivity and Performance Management, v. 58, n. 2, p. 160173, 2009.

HORSTMAN, A.; WITTEVEEN, W. Performance Indicators in the Best Value Approach. Advanced of Performance Information \& Value, v. 5, n. 2, p. 59-78, 2013.

HORTA, I. M.; CAMANHO, A. S.; COSTA, J. M. DA. Performance Assessment of Construction Companies Integrating Key Performance Indicators and Data Envelopment Analysis. Journal of Construction Engineering and Management, v. 136, n. 5, p. 581-594, 2010.

JIN, Z. et al. Practical Framework for Measuring Performance of International Construction Firms. Journal of Construction Engineering and Management, v. 139, n. 9, p. 1154-1167, 2013.

KAGIOGLOU, M.; COOPER, R.; AQUAD, G. Performance Management in Construction: a conceptual framework. Construction Management and Economics, v. 19, p. 85-95, 2001.

KAPLAN, R. S.; NORTON, D. P. The Balanced Scorecard: measures that drive performance. Havard Business Review, v. 70, n. 1, p. 70-79, 1992.

KAPLAN, R. S.; NORTON, D. P. Using the Balanced Scorecard as a Strategic Management System. Harvard Business Review, v. 74, n. 1, p. 75-85, 1996.
KENNERLEY, M.; NEELY, A. A Framework of the Factors Affecting the Evolution of Performance Measurement Systems. International Journal of Operations \& Production Management, v. 22, n. 11, p. 12221245, 2002.

KRIPPENDORFF, K. Content Analysis: an introduction to its methodology. 2. ed. London: Sage Publications, 2004.

LEBAS, M. J. Performance Measurement and Performance Management. International Journal of Production Economics, v. 41, n. 1, p. 23-35, 1995.

LUU, T.-V. et al. Performance Measurement of Construction Firms in Developing Countries. Construction Management and Economics, v. 26, n. 4, p. 373-386, 2008.

NEELY, A. et al. Designing Performance Measures: a structured approach. International Journal of Operations \& Production Management, v. 17, n. 11, p. 1131-1152, 1997.

NEELY, A. The Performance Measurement Revolution: why now and what next? International Journal of Operations \& Production Management, v. 19, n. 2, p. 205-228, 1999.

NEELY, A. et al. Performance Measurement System Design: developing and testing a processbased approach. International Journal of Operations \& Production Management, v. 20, n. 10, p. 1119-1145, 2000.

NEELY, A.; BOURNE, M. Why Measurement Initiatives Fail. Measuring Business Excellence, v. 4, n. 4, p. 3-7, 2000.

NEELY, A.; GREGORY, M.; PLATTS, K. Performance Measuremente System Design: a literature review and research agenda.

International Journal of Operations \& Production Management, v. 15, n. 4, p. 80-116, 1995.

NUDURUPATI, S.; ARSHAD, T.; TURNER, T. Performance Measurement in the Construction Industry: an action case investigating manufacturing methodologies. Computers in Industry, v. 58, n. 7, p. 667-676, set. 2007.

PEKURI, A.; HAAPASALO, H.; HERRALA, M. Productivity and Performance Management: managerial practices in the construction industry. International Journal of Performance Mearusement, v. 1, p. 39-58, 2011.

RICHARDSON, R. J. Pesquisa Social: métodos e técnicas. 3. ed. São Paulo: Atlas, 2011. 
ROBINSON, H. S. et al. Business Performance Measurement Practices in Construction Engineering Organisations. Measuring Business Excellence, v. 9, n. 1, p. 13-22, 2005.

SHENHAR, A. J.; LEVY, O.; DVIR, D. Mapping the Dimensions of Project Sucess. Project Management Journal, v. 28, n. 2, p. 5-13, 1997.

SINK, D. S.; TUTTLE, T. C. Planejamento e Medição Para Performance. Rio de Janeiro: Qualitymark, 1993.

SKIBNIEWSKI, M. J.; GHOSH, S. Determination of Key Performance Indicators with Enterprise Resource Planning Systems in Engineering Construction Firms. Journal of Construction Engineering and Management, v. 135, n. 10, p. 965-978, 2009.
TOOR, S. R.; OGUNLANA, S. O. Beyond the "Iron Triangle": stakeholder perception of key performance indicators (KPIs) for large-scale public sector development projects. International Journal of Project Management, v. 28, n. 3, p. 228-236, 2010.

VITALE, M.; MAVRINAC, S. C.; HAUSER, M. Process/Financial Scorecard: a strategic performance measurement system. Planning Review, v. 22, n. 12, p. 12-16, 1994.

WEGELIUS-LEHTONEN, T. Performance Measurement in Construction Logistics. International Journal of Production Economics, v. 69, n. 1, p. 107-116, 2001.

YU, I. et al. Comparable Performance Measurement Sytem for Construction Companies. Journal of Management in Engineering, v. 23, n. 3, p. 131-139, 2007.

\footnotetext{
Luís Felipe Cândido

Programa de Pós-Graduação em Engenharia Civil | Universidade Federal do Ceará | Campus Universitário do Pici, Bloco 728, térreo | Fortaleza - CE - Brasil | CEP 60455-900 | Tel.: (85) 99998-9289 | E-mail: luisfcandido2015@gmail.com

Sérgio Henrique de Oliveira Lima

Programa de Pós-Graduação em Administração e Controladoria | Universidade Federal do Ceará | Av. da Universidade, 2431, Benfica | Fortaleza - CE - Brasil | CEP 60020-180 | Tel.: (85) 98821-5371 | E-mail: shlima05@gmail.com

José de Paula Barros Neto

Departamento de Engenharia Estrutural e Construcão Civil, Centro de Tecnologia | Universidade Federal do Ceará | Campus do Pici, s/n, Bloco 710, Pici | Fortaleza - CE - Brasil | CEP 60455-760 | Tel.: (85) 3366-9600 | E-mail: barrosneto@gercon.ufc.br
}

Revista Ambiente Construído

Associação Nacional de Tecnologia do Ambiente Construído

Av. Osvaldo Aranha, $99-3^{\circ}$ andar, Centro

Porto Alegre - RS - Brasil

CEP $90035-190$

Telefone: +55 (51) 3308-4084

Fax: +55 (51) 3308-4054

www.seer.ufrgs.br/ambienteconstruido

E-mail: ambienteconstruido@ufrgs.br 


\section{APÊNDICE A - Caterísticas gerais dos modelos de medição analisados}

Quadro 5 - Características gerais dos modelos de medição analisados (Continua...)

\begin{tabular}{|c|c|c|c|c|c|c|c|c|}
\hline Pesquisadores & $\begin{array}{c}\text { Motivo/objetivo } \\
\text { da criação }\end{array}$ & $\begin{array}{l}\text { Dimensões de } \\
\text { desempenho } \\
\text { (framework } \\
\text { estrutural) }\end{array}$ & $\begin{array}{l}\text { Conjunto de passos para } \\
\text { a concepção do sistema } \\
\text { (framework processual) }\end{array}$ & $\begin{array}{l}\text { Vinculação } \\
\text { com a } \\
\text { estratégia? }\end{array}$ & $\begin{array}{c}\text { Abrangência } \\
\text { (processos } \\
\text { específicos, } \\
\text { empreendimento, } \\
\text { organização) }\end{array}$ & $\begin{array}{l}\text { Indicadores } \\
\text { específicos }\end{array}$ & $\begin{array}{l}\text { Outros elementos } \\
\text { para distinguir os } \\
\text { indicadores? }\end{array}$ & $\begin{array}{c}\text { Dinâmico } \\
\text { (ou seja, } \\
\text { pode ser } \\
\text { atualizado?) }\end{array}$ \\
\hline $\begin{array}{c}\text { Alarcón e } \\
\text { Ashley (1996) }\end{array}$ & $\begin{array}{l}\text { Modelagem e } \\
\text { avaliação do } \\
\text { desempenho de } \\
\text { empreendimento } \\
\text { de construção }\end{array}$ & $\begin{array}{l}\text { (1) custos; (2) } \\
\text { programąăo; (3) } \\
\text { resultados do } \\
\text { projeto para o } \\
\text { cliente; (4) } \\
\text { efetividade da } \\
\text { gestão }\end{array}$ & $\begin{array}{c}\text { (1) avaliação das } \\
\text { caracteristicas da } \\
\text { organização, sua } \\
\text { estratégia e as } \\
\text { possiblidades de impacto } \\
\text { no projeto (2) } \\
\text { especificação das } \\
\text { características do projeto } \\
\text { e seus impactos; (3) } \\
\text { Seleção dos indicadores; e } \\
\text { (4) tomada de decisão } \\
\text { baseada em um único } \\
\text { indicador ou na } \\
\text { combinação de múltiplos } \\
\text { indicadores }\end{array}$ & Sim & Empreendimento & Não & $\begin{array}{c}\text { Propõe um padrão } \\
\text { para definição dos } \\
\text { indicadores, além de } \\
\text { uma matriz de } \\
\text { impacto entre as } \\
\text { caracteristicas da } \\
\text { organização e seus } \\
\text { impactos nos } \\
\text { resultados esperados } \\
\text { dos projetos }\end{array}$ & Sim \\
\hline $\begin{array}{l}\text { Wegelius- } \\
\text { Lehtonen } \\
\text { (2001) }\end{array}$ & $\begin{array}{l}\text { Necessidade de } \\
\text { medir o } \\
\text { desempenho da } \\
\text { logística da } \\
\text { construção }\end{array}$ & Não & Não & Não & Processo específico & Não & $\begin{array}{c}\text { Sim, agrupa os } \\
\text { indicadores pelo seu } \\
\text { uso (de } \\
\text { monitoramento ou } \\
\text { melhoria) ou foco } \\
\text { (em nivel de } \\
\text { organização, projeto } \\
\text { ou subcontratos } \\
\text { especíicos) }\end{array}$ & Sim \\
\hline $\begin{array}{l}\text { Kagioulou, } \\
\text { Cooper e } \\
\text { Aquad (2001) }\end{array}$ & $\begin{array}{l}\text { Necessidade de } \\
\text { relacionar } \\
\text { efetivamente } \\
\text { objetivos/ metas } \\
\text { estratégicas a } \\
\text { indicadores } \\
\text { operacionais em } \\
\text { empresas de } \\
\text { construção }\end{array}$ & $\begin{array}{l}\text { Baseado no BSC: } \\
\text { (1) financeira, (2) } \\
\text { processos } \\
\text { internos, (3) } \\
\text { aprendizagem e } \\
\text { crescimento e (4) } \\
\text { clientes (5) } \\
\text { perspectivas e (6) } \\
\text { projetistas e } \\
\text { fornecedores. }\end{array}$ & $\begin{array}{c}5 \text { passos desde o } \\
\text { desenvolvimento da } \\
\text { estratégia organizacional } \\
\text { e desenvolvimento dos } \\
\text { indicadores }\end{array}$ & Sim & $\begin{array}{c}\text { Organização e } \\
\text { empreendimento }\end{array}$ & Não & $\begin{array}{c}\text { Fornece um modelo } \\
\text { para apresentação e } \\
\text { ponderação entre os } \\
\text { indicadores de } \\
\text { desempenho e suas } \\
\text { perspectivas de } \\
\text { desempenho (escala } \\
\text { de } 1 \text { a 5), mostrando } \\
\text { a importância de } \\
\text { indicadores } \\
\text { especificos no } \\
\text { alcance dos } \\
\text { objetivos } \\
\text { organizacionais }\end{array}$ & Sim \\
\hline $\begin{array}{l}\text { Arditi e Lee } \\
\text { (2003) }\end{array}$ & $\begin{array}{l}\text { Necessidade de } \\
\text { melhorar a } \\
\text { medição em } \\
\text { empresas que } \\
\text { aplicam conceitos } \\
\text { de qualidade total }\end{array}$ & $\begin{array}{l}\text { Baseado em } \\
\text { conceitos da } \\
\text { qualidade (QFD), } \\
\text { relaciona os } \\
\text { fatores de } \\
\text { qualidade do } \\
\text { serviço com os } \\
\text { componentes do } \\
\text { sistema de } \\
\text { qualidade a partir } \\
\text { do Malcolm } \\
\text { Baldrige } \\
\text { National Quality } \\
\text { Award } \\
\text { (MBNOA) }\end{array}$ & $\begin{array}{l}\text { (1) identificação dos } \\
\text { requisitos dos clientes e } \\
\text { coleta de dados } \\
\text { (2) processamento dos } \\
\text { dados } \\
\text { (3) calculando o nivel } \\
\text { máximo alcançável de } \\
\text { desempenho } \\
\text { (4) calcular o nivel real de } \\
\text { desempenho da firma } \\
\text { (5) classificar as empresas } \\
\text { de acordo com seu } \\
\text { desempenho relativo }\end{array}$ & Sim & Organização & $\begin{array}{l}10 \text { critérios } \\
\text { de qualidade }\end{array}$ & Não & Não \\
\hline $\begin{array}{l}\text { Bassioni, Price } \\
\text { e Hassan } \\
\text { (2005) }\end{array}$ & $\begin{array}{l}\text { Necessidade de } \\
\text { vincular os fatores } \\
\text { de sucesso aos } \\
\text { rsultados obtidos } \\
\text { em uma empresa } \\
\text { de construção }\end{array}$ & $\begin{array}{c}\text { Baseado no BSC, } \\
\text { no EFQM e no } \\
\text { Modelo de } \\
\text { excelência de } \\
\text { negócios de } \\
\text { Baldrige } \\
\\
\text { (1) desempenho } \\
\text { das pessoas, } \\
\text { parcerias e } \\
\text { fornecedores; (2) } \\
\text { resultados do } \\
\text { empreendimento, } \\
\text { (3) resultados } \\
\text { para os clientes e } \\
\text { (4) resultados } \\
\text { para sociedade }\end{array}$ & $\begin{array}{l}\text { Estabelece um amplo } \\
\text { quadro de fatores de } \\
\text { sucesso que devem ser } \\
\text { relacionados aos } \\
\text { resultados obtidos em um } \\
\text { processo duplo de } \\
\text { medição, estabelecendo } \\
\text { método de medição para } \\
\text { ambos os componentes do } \\
\text { modelo. }\end{array}$ & Sim & Organização & Não & Não & Sim \\
\hline
\end{tabular}




\section{Quadro 5 - Características gerais dos modelos de medição analisados (continuação)}

\begin{tabular}{|c|c|c|c|c|c|c|c|c|}
\hline Pesquisadores & $\begin{array}{c}\text { Motivo/objetivo } \\
\text { da criação }\end{array}$ & $\begin{array}{l}\text { Dimensões de } \\
\text { desempenho } \\
\text { (framework } \\
\text { estrutural) }\end{array}$ & $\begin{array}{l}\text { Conjunto de passos para } \\
\text { a concepção do sistema } \\
\text { (framework processual) }\end{array}$ & $\begin{array}{l}\text { Vinculação } \\
\text { com a } \\
\text { estratégia? }\end{array}$ & $\begin{array}{c}\text { Abrangência } \\
\text { (processos } \\
\text { específicos, } \\
\text { empreendimento, } \\
\text { organização) }\end{array}$ & $\begin{array}{l}\text { Indicadores } \\
\text { específicos }\end{array}$ & $\begin{array}{l}\text { Outros elementos } \\
\text { para distinguir os } \\
\text { indicadores? }\end{array}$ & $\begin{array}{l}\text { Dinâmico } \\
\text { (ou seja, } \\
\text { pode ser } \\
\text { atualizado?) }\end{array}$ \\
\hline $\begin{array}{l}\text { Chan e Chan } \\
\text { (2004) }\end{array}$ & $\begin{array}{l}\text { Necessidade de } \\
\text { melhorar os } \\
\text { critérios para } \\
\text { definição de } \\
\text { sucesso de } \\
\text { empreendimentos } \\
\text { de construção }\end{array}$ & $\begin{array}{c}\text { Baseado em } \\
\text { KPIs, } \\
\text { subdividindo-os } \\
\text { em: a) } \\
\text { indicadores } \\
\text { objetivos e b) } \\
\text { indicadores } \\
\text { subjetivos }\end{array}$ & $\begin{array}{l}\text { Não, os autores apenas } \\
\text { apresentam os indicadores } \\
\text { para as dimensões } \\
\text { mapeadas }\end{array}$ & Não & Empreendimento & $\begin{array}{c}10 \\
\text { indicadores }\end{array}$ & Não & Sim \\
\hline $\begin{array}{l}\text { Beatham et al. } \\
\quad(2005)\end{array}$ & \begin{tabular}{|c|} 
Necessidade de \\
sistematizar a \\
melhoria continua \\
para medição de \\
desempenho \\
incorporando \\
elementos de \\
qualidade baseado \\
no EFQM \\
\end{tabular} & \begin{tabular}{|} 
Baseado no \\
EFQM e no BSC: \\
(1) financeira, (2) \\
processos \\
internos, (3) \\
aprendizagem e \\
crescimento e (4) \\
clientes
\end{tabular} & $\begin{array}{c}\text { Sistema de medição em } \\
\text { dois ciclos chamados de } \\
\text { RADAR: } \\
\text { - ciclo 1: implantação das } \\
\text { medidas } \\
\text { - ciclo 2: mudanças } \\
\text { impulsionadas pelos } \\
\text { resultados }\end{array}$ & Sim & Organização & Não & Não & $\begin{array}{c}\text { Sim, o } \\
\text { modelo } \\
\text { apresenta } \\
\text { um ciclo } \\
\text { duplo } \\
\text { revisão } \\
\text { sistemática } \\
\text { chamado de } \\
\text { RADAR }\end{array}$ \\
\hline $\begin{array}{c}\text { Georgy, } \\
\text { Chang e } \\
\text { Zhang (2005) } \\
\end{array}$ & \begin{tabular}{|c|} 
Necessidade de \\
melhorar a \\
medição e \\
avaliação do \\
desempenho do \\
processo de projeto \\
para construção \\
\end{tabular} & Não & $\begin{array}{l}\text { Sim, seleciona os } \\
\text { indicadores a partir do CII } \\
\text { e desenvolve uma função } \\
\text { de utilidade para propor } \\
\text { uma função de } \\
\text { desempenho }\end{array}$ & Não & $\begin{array}{l}\text { Processos } \\
\text { específicos }\end{array}$ & Sim & Não & Não \\
\hline $\begin{array}{c}\text { El-Mashaleh, } \\
\text { Minchin Jre } \\
\text { O'Brien (2007) }\end{array}$ & $\begin{array}{c}\text { Necessidade de um } \\
\text { modelo de } \\
\text { benchmarking } \\
\text { matematicamente } \\
\text { mais rigoroso }\end{array}$ & \begin{tabular}{|} 
(1) tempo, (2) \\
custo, (3) \\
segurança, (4) \\
clientes e (5) \\
lucro
\end{tabular} & Não & Não & $\begin{array}{c}\text { Organização e } \\
\text { empreendimento }\end{array}$ & 7 indicadores & Não & Não \\
\hline $\begin{array}{l}\text { Nudurupati, } \\
\text { Arshad e } \\
\text { Turner (2007) }\end{array}$ & $\begin{array}{l}\text { Necessidade de } \\
\text { estender a visão } \\
\text { para gestão de } \\
\text { operações de uma } \\
\text { empresa de } \\
\text { construção }\end{array}$ & \begin{tabular}{|c|} 
Baseado no BSC: \\
(1) financeira, (2) \\
processos \\
internos, (3) \\
aprendizagem e \\
crescimento e (4) \\
clientes
\end{tabular} & $\begin{array}{c}\text { (1) Focar o negócio nas } \\
\text { necessidades de todos os } \\
\text { stakeholders (internos e } \\
\text { externos); (2) criar a visão } \\
\text { de causa e efeito entre as } \\
\text { medidas operacionais e } \\
\end{array}$ & Sim & $\begin{array}{l}\text { Organização e } \\
\text { empreendimento }\end{array}$ & $\begin{array}{c}20 \\
\text { indicadores }\end{array}$ & Não & Sim \\
\hline $\begin{array}{l}\text { Yu et al. } \\
(2007)\end{array}$ & \begin{tabular}{|c|} 
Necessidade de um \\
modelo de \\
benchmarking que \\
permita a avaliação \\
do desempenho \\
geral em um único \\
parâmetro \\
agregado \\
\end{tabular} & \begin{tabular}{|} 
Baseado no BSC: \\
(1) financeira, (2) \\
processos \\
internos, (3) \\
aprendizagem e \\
crescimento e (4) \\
clientes
\end{tabular} & $\begin{array}{l}\text { Seleção e definição dos } \\
\text { indicadores }\end{array}$ & Sim & Organização & $\begin{array}{c}12 \text { critérios e } \\
16 \\
\text { indicadores }\end{array}$ & $\begin{array}{c}\text { Explicita um método } \\
\text { quantitativo para o } \\
\text { estabelecimento das } \\
\text { relações de causa e } \\
\text { efeito entre } \\
\text { indicadores }\end{array}$ & Sim \\
\hline $\begin{array}{l}\text { Luu et al. } \\
\text { (2008) }\end{array}$ & $\begin{array}{l}\text { Necessidade de } \\
\text { melhorar o } \\
\text { desempenho da } \\
\text { indústria da } \\
\text { construção } \\
\text { Vietnamita }\end{array}$ & $\begin{array}{l}\text { Baseado no BSC: } \\
\text { (1) financeira, (2) } \\
\text { processos } \\
\text { internos, (3) } \\
\text { aprendizagem e } \\
\text { crescimento e (4) } \\
\text { clientes }\end{array}$ & $\begin{array}{l}\text { Formulação da estratégia } \\
\text { da empresa, identificação } \\
\text { e validação dos KPI a } \\
\text { medição e avaliação do } \\
\text { desempenho estratégico }\end{array}$ & Sim & Organização & $\begin{array}{c}30 \\
\text { indicadores }\end{array}$ & \begin{tabular}{|c|} 
Explicita um método \\
quantitativo para o \\
estabelecimento das \\
relações de causa e \\
efeito entre \\
indicadores na \\
mesma dimensão ou \\
em diferentes \\
dimensões de \\
desempenho \\
\end{tabular} & Sim \\
\hline $\begin{array}{l}\text { Haponava e } \\
\text { Al-jibouri } \\
\text { (2009) }\end{array}$ & $\begin{array}{l}\text { Necessidade de } \\
\text { identificar } \\
\text { indicadores de } \\
\text { desempenho } \\
\text { baseado em } \\
\text { processos para } \\
\text { aplicação no } \\
\text { controle da fase de } \\
\text { pré-construção }\end{array}$ & Não & $\begin{array}{l}\text { Não, apresenta apenas } \\
\text { procedimentos que podem } \\
\text { ser desenvolvidos }\end{array}$ & Não & Empreendimento & 5 indicadores & Não & Não \\
\hline $\begin{array}{l}\text { Skibniewski e } \\
\text { Ghosh (2009) }\end{array}$ & \begin{tabular}{|c|} 
Analisar a \\
contribuiçãa de \\
sistemas ERP para \\
medição de \\
desempenho a \\
partir do CBPP
\end{tabular} & $\begin{array}{c}\text { (1) custo, (2) } \\
\text { tempo, (3) } \\
\text { qualidade, (4) } \\
\text { satisfação dos } \\
\text { clientes, (5) } \\
\text { segurança, (6) } \\
\text { lucratividade e } \\
\text { (7) produtividade }\end{array}$ & $\begin{array}{c}\text { Sim, } 6 \text { etapas, desde o } \\
\text { mapeamento do processo } \\
\text { de negócio e os } \\
\text { indicadores associados a } \\
\text { cada etapa, coleta dos } \\
\text { dados e cálculo dos } \\
\text { indicadores até a tomada } \\
\text { de decisão }\end{array}$ & Não & Empreendimento & 7 indicadores & $\begin{array}{l}\text { Sim, propuseram } \\
\text { uma taxonomia para } \\
\text { os indicadores } \\
\text { conforme a urgência } \\
\text { da informação (time- } \\
\text { sensitive analysis) }\end{array}$ & Sim \\
\hline
\end{tabular}




\section{Quadro 5 - Características gerais dos modelos de medição analisados (conclusão)}

\begin{tabular}{|c|c|c|c|c|c|c|c|c|}
\hline Pesquisadores & $\begin{array}{l}\text { Motivo/objetivo } \\
\text { da criação }\end{array}$ & $\begin{array}{l}\text { Dimensões de } \\
\text { desempenho } \\
\text { (framework } \\
\text { estrutural) }\end{array}$ & $\begin{array}{l}\text { Conjunto de passos para } \\
\text { a concepção do sistema } \\
\text { (framework processual) }\end{array}$ & $\begin{array}{l}\text { Vinculação } \\
\text { com a } \\
\text { estratégia? }\end{array}$ & $\begin{array}{l}\text { Abrangência } \\
\text { (processos } \\
\text { específicos, } \\
\text { empreendimento, } \\
\text { organização) }\end{array}$ & $\begin{array}{l}\text { Indicadores } \\
\text { específicos }\end{array}$ & $\begin{array}{l}\text { Outros elementos } \\
\text { para distinguir os } \\
\text { indicadores? }\end{array}$ & $\begin{array}{l}\text { Dinâmico } \\
\text { (ou seja, } \\
\text { pode ser } \\
\text { atualizado?) }\end{array}$ \\
\hline $\begin{array}{c}\text { Horta, } \\
\text { Camanho e } \\
\text { Costa (2010) }\end{array}$ & $\begin{array}{c}\text { Necessidade de um } \\
\text { modelo de } \\
\text { benchmarking } \\
\text { matematicamente } \\
\text { mais rigoroso } \\
\text { incorporando a } \\
\text { visão de fronteira } \\
\text { de eficiência e } \\
\text { habilitando a } \\
\text { análise cruzada de } \\
\text { aspectos } \\
\text { operacionais e } \\
\text { estratégicos } \\
\end{array}$ & $\begin{array}{l}\text { (1) desempenho } \\
\text { organizacional e } \\
\text { (2) desempenho } \\
\text { operacional }\end{array}$ & Não & Sim & $\begin{array}{l}\text { Organização e } \\
\text { empreendimento }\end{array}$ & 5 indicadores & Não & Não \\
\hline $\begin{array}{l}\text { Costa e } \\
\text { Formoso } \\
(2011)\end{array}$ & $\begin{array}{c}\text { Clube de } \\
\text { Benchmarking para } \\
\text { indústria da } \\
\text { construção no } \\
\text { Brasil }\end{array}$ & $\begin{array}{c}\text { (1) produção e } \\
\text { segurança; (2) } \\
\text { cliente; (3) } \\
\text { vendas; (4) } \\
\text { fornecedores; (5) } \\
\text { qualidade; e (6) } \\
\text { pessoas }\end{array}$ & $\begin{array}{c}\text { Dá subsídios para etapa } \\
\text { de seleção e definição e } \\
\text { coleta e processamento } \\
\text { dos dados }\end{array}$ & Sim & $\begin{array}{l}\text { Empreendimento e } \\
\text { organização }\end{array}$ & $\begin{array}{c}18 \\
\text { indicadores }\end{array}$ & $\begin{array}{l}\text { Classifica-os em } \\
\text { indicadores de } \\
\text { resultado e } \\
\text { indicadores de } \\
\text { processo }\end{array}$ & Sim \\
\hline $\begin{array}{l}\text { Lin } e \text { al } \text {. } \\
\text { (2011) }\end{array}$ & $\begin{array}{c}\text { Identificar os } \\
\text { principais } \\
\text { indicadores de } \\
\text { desempenho para } \\
\text { estudos de gestão } \\
\text { de valor }\end{array}$ & $\begin{array}{c}\text { (1) indicadores de } \\
\text { previsão; (2) } \\
\text { indicadores de } \\
\text { desempenho do } \\
\text { processo; (3) } \\
\text { indicadores de } \\
\text { resultado } \\
\text { (dividido em } \\
\text { aspectos } \\
\text { tangiveis e } \\
\text { intangiveis) }\end{array}$ & $\begin{array}{l}\text { Sim, forneceu subsidios } \\
\text { para etapa de seleção e } \\
\text { coleta e processamento } \\
\text { dos dados }\end{array}$ & Não & Empreendimento & $\begin{array}{c}18 \\
\text { indicadores }\end{array}$ & $\begin{array}{l}\text { Sim, forneceu uma } \\
\text { lista de fontes de } \\
\text { coleta de dados para } \\
\text { os vários } \\
\text { indicadores e } \\
\text { participantes do } \\
\text { processo } \\
\text { (facilitadores, } \\
\text { clientes e } \\
\text { participantes do } \\
\text { estudo de valor) } \\
\end{array}$ & Não \\
\hline $\begin{array}{l}\text { Ozorhon et al. } \\
\quad \text { (2011) }\end{array}$ & $\begin{array}{c}\text { Medir o } \\
\text { desempenho de } \\
\text { empresas atuando } \\
\text { sob regime de } \\
\text { joimt-venture } \\
\text { internacional (IJV) }\end{array}$ & \begin{tabular}{|c|} 
(1) desempenho \\
do projeto; (2) \\
desempenho da \\
gestão do IJV \\
(International \\
Joint Venture); \\
(3) desempenho \\
dos parceiros; (4) \\
satisfaçăo com a \\
IJV \\
\end{tabular} & Não & Não & $\begin{array}{l}\text { Organização e } \\
\text { empreendimento }\end{array}$ & $\begin{array}{c}17 \\
\text { indicadores }\end{array}$ & Não & Não \\
\hline $\begin{array}{l}\text { Halman e } \\
\text { Voordijk } \\
\text { (2012) }\end{array}$ & $\begin{array}{l}\text { Desenvolver um } \\
\text { modelo de } \\
\text { medição de } \\
\text { desempenho da } \\
\text { cadeia de } \\
\text { suprimentos }\end{array}$ & $\begin{array}{c}\text { Baseado no BSC, } \\
\text { acrescentando as } \\
\text { perspectivas de } \\
\text { processos } \\
\text { externos e } \\
\text { inovação }\end{array}$ & $\begin{array}{l}\text { Apenas para seleção dos } \\
\text { indicadores }\end{array}$ & Sim & Organização & $\begin{array}{c}45 \\
\text { indicadores }\end{array}$ & Não & Sim \\
\hline $\begin{array}{c}\text { Heravi e } \\
\text { Ilbeigi (2012) }\end{array}$ & $\begin{array}{l}\text { Necessidade de } \\
\text { melhorias para } \\
\text { avaliação } \\
\text { quantitativa do } \\
\text { sucesso de } \\
\text { empreendimentos } \\
\text { de construção } \\
\text { incorporando a } \\
\text { visão da gestão de } \\
\text { projetos }\end{array}$ & $\begin{array}{l}\text { Sucesso do } \\
\text { projeto e sucesso } \\
\text { da gestão do } \\
\text { projeto }\end{array}$ & $\begin{array}{c}\text { Definição, coleta } \mathrm{e} \\
\text { processamento dos dados }\end{array}$ & Não & Empreendimento & $\begin{array}{c}11 \\
\text { indicadores }\end{array}$ & Não & Não \\
\hline $\begin{array}{l}\text { Jin et al. } \\
(2013)\end{array}$ & $\begin{array}{l}\text { Necessidade de } \\
\text { medição de } \\
\text { desempenho para } \\
\text { empresas de } \\
\text { construção } \\
\text { multinacionais }\end{array}$ & $\begin{array}{l}\text { Baseado no BSC, } \\
\text { acrescentando as } \\
\text { perspectivas de } \\
\text { desempenho de } \\
\text { mercado e } \\
\text { stakeholders }\end{array}$ & $\begin{array}{c}\text { Definição e } \\
\text { processamento dos dados }\end{array}$ & Sim & Organização & $\begin{array}{c}27 \\
\text { indicadores }\end{array}$ & $\begin{array}{c}\text { Sim, o peso relativo } \\
\text { de cada indicador } \\
\text { proposto por meio } \\
\text { de uma survey com } \\
117 \text { participantes } \\
\text { (profissionais e } \\
\text { acadêmicos) }\end{array}$ & Não \\
\hline $\begin{array}{l}\text { Yeung et al. } \\
\text { (2013) }\end{array}$ & $\begin{array}{l}\text { Desenvolver um } \\
\text { modelo de } \\
\text { benchmarking em } \\
\text { Hong Kong }\end{array}$ & Não & Não & Sim & $\begin{array}{c}\text { Organização e } \\
\text { empreendimento }\end{array}$ & $\begin{array}{c}10 \\
\text { indicadores }\end{array}$ & $\begin{array}{c}\text { Método para } \\
\text { determinar a relação } \\
\text { entre os indicadores } \\
\text { e o peso relativo de } \\
\text { cada deles e } \\
\text { desenvolve uma } \\
\text { equação de } \\
\text { desempenho geral }\end{array}$ & Não \\
\hline
\end{tabular}

